\title{
Modulators of mercury risk to wildlife and humans in the context of rapid global change
}

\author{
Collin A. Eagles-Smith, Ellen K. Silbergeld, Niladri Basu, \\ Paco Bustamante, Fernando Diaz-Barriga, William A. Hopkins, \\ Karen A. Kidd, Jennifer F. Nyland
}

Published online: 31 January 2018

\begin{abstract}
Environmental mercury $(\mathrm{Hg})$ contamination is an urgent global health threat. The complexity of $\mathrm{Hg}$ in the environment can hinder accurate determination of ecological and human health risks, particularly within the context of the rapid global changes that are altering many ecological processes, socioeconomic patterns, and other factors like infectious disease incidence, which can affect $\mathrm{Hg}$ exposures and health outcomes. However, the success of global Hg-reduction efforts depends on accurate assessments of their effectiveness in reducing health risks. In this paper, we examine the role that key extrinsic and intrinsic drivers play on several aspects of $\mathrm{Hg}$ risk to humans and organisms in the environment. We do so within three key domains of ecological and human health risk. First, we examine how extrinsic global change drivers influence pathways of $\mathrm{Hg}$ bioaccumulation and biomagnification through food webs. Next, we describe how extrinsic socioeconomic drivers at a global scale, and intrinsic individual-level drivers, influence human $\mathrm{Hg}$ exposure. Finally, we address how the adverse health effects of $\mathrm{Hg}$ in humans and wildlife are modulated by a range of extrinsic and intrinsic drivers within the context of rapid global change. Incorporating components of these three domains into research and monitoring will facilitate a more holistic understanding of how ecological and societal drivers interact to influence $\mathrm{Hg}$ health risks.
\end{abstract}

Keywords ASGM - Biomagnification · Fisheries · Immunotoxicity · Invasive species · Microbiome · Selenium

Niladri Basu, Paco Bustamante, Fernando Diaz-Barriga, William A. Hopkins, Karen A. Kidd, Jennifer F. Nyland contributed equally to the work.

\section{INTRODUCTION}

The health effects of mercury $(\mathrm{Hg})$ exposure represent a significant threat to ecosystems and human welfare worldwide (Driscoll et al. 2013), but understanding the risks associated with $\mathrm{Hg}$ exposure is complicated by this element's varied environmental fate and the overarching influences of environmental, biological, and socioeconomic drivers. In its various forms, $\mathrm{Hg}$ causes immunotoxicity (Hawley et al. 2009; Lewis et al. 2013; Hui et al. 2016; Zhang et al. 2016; Crowe et al. 2017) and nephrotoxicity (Tchounwou et al. 2003), diminishes neurological capacity and neurobehavioral function (Steuerwald et al. 2000; Basu et al. 2005; Clarkson and Magos 2006; Mergler et al. 2007; Scheuhammer and Sandheinrich 2008; Depew et al. 2012a; Bridges et al. 2016; Landler et al. 2017), alters functioning of three major endocrine axes (Wada et al. 2009; Meyer et al. 2014), and impairs reproduction and alters offspring quality (Klaper et al. 2006; Burgess and Meyer 2008; Bergeron et al. 2011; Hopkins et al. 2013; Tartu et al. 2013; Thompson et al. in press). The numerous adverse health effects of $\mathrm{Hg}$, coupled with the diverse environmental sources, propensity for long-range transport, complex biogeochemical cycling, and various exposure pathways through food webs and from industrial activities present significant challenges to characterizing and managing the risk of $\mathrm{Hg}$ exposure to ecological and public health. Nonetheless, substantial progress has been made over the past several decades, resulting in improved inventories of $\mathrm{Hg}$ sources and releases (Streets et al. 2017), and a more robust scientific understanding of the factors influencing $\mathrm{Hg}$ fate and transport (see companion paper by Obrist et al. (2018), the processes driving methylmercury ( $\mathrm{MeHg}$ ) production (see companion paper by Hsu-Kim et al. (2018), and the manifestations and mechanisms of many of the 
toxic effects of $\mathrm{Hg}$ in biota. This progress has supported global efforts to reduce $\mathrm{Hg}$ loading to the environment for protection of human and ecological health, such as those put forth at the Minamata Convention (see companion paper by Selin et al. (2018).

Ecological and public health risks posed by $\mathrm{Hg}$ rarely follow a simple linear relationship from $\mathrm{Hg}$ releases, to uptake and exposure, to adverse health outcomes. Instead, a diverse suite of extrinsic ecological and socioeconomic factors (herein called "extrinsic drivers," e.g., invasive species, culture) and intrinsic biological factors (herein called "intrinsic drivers," e.g., genetics, microbiome) alter the availability of $\mathrm{Hg}$ for biological uptake, and modify $\mathrm{Hg}$ toxicity to humans and other animals. Some of these drivers-e.g., climate change, land use changes-are occurring at unprecedented global rates and challenge the development of effective $\mathrm{Hg}$ control actions, alter recovery trajectories, and confound interpretations of monitoring outcomes. The growing extent and intensity of some drivers will continue to influence key processes associated with $\mathrm{Hg}$ exposure and bioaccumulation in humans and other animals; thus, there is a critical need to understand how these drivers alter mechanisms of $\mathrm{Hg}$ bioavailability in order to better predict changes in $\mathrm{Hg}$ exposure trajectories and mitigate adverse health effects.

Exposure to $\mathrm{MeHg}$ mainly occurs via the diet for most organisms (Mergler et al. 2007; Wiener 2013), whereas inorganic $\mathrm{Hg}$ (elemental $\left(\mathrm{Hg}^{0}\right)$ and ionic $\mathrm{Hg}\left(\mathrm{Hg}^{\mathrm{II}}\right)$ ) exposures (particularly in humans) largely occur through inhalation, dermal, or oral routes (Clarkson and Magos 2006), which are primarily associated with industrial processes, such as artisanal and small-scale gold mining (ASGM) (Steckling et al. 2011; Basu et al. 2015b), and medical uses (Clarkson and Magos 2006). Exposures to both organic and inorganic $\mathrm{Hg}$ species are influenced by the environmental alterations and societal shifts associated with extrinsic drivers (such as hydrologic and landuse alterations, invasive species, climate change, and macroeconomic change), but through very different mechanisms. For example, extrinsic drivers that alter trophic processes, e.g., food web structure, foraging ecology, and ecosystem energetics (i.e., energy flow through food webs), influence the magnitude of $\mathrm{MeHg}$ bioaccumulation and biomagnification through food webs (Vander Zanden and Rasmussen 1996; Lavoie et al. 2013; Karimi et al. 2016a; Polito et al. 2016). Conversely, other extrinsic drivers, such as shifts in global socioeconomic trends, cultural patterns, and development trajectories, affect risks of inorganic $\mathrm{Hg}$ exposure in human populations (Swain et al. 2007). It is important to also recognize the critical roles of abiotic $\mathrm{Hg}$ fate and transport and $\mathrm{MeHg}$ production in the $\mathrm{Hg}$ cycle, as well as their contributions to $\mathrm{Hg}$ exposure and health risks. Although we do not address those processes here, as they are reviewed in detail elsewhere (Hsu-Kim et al. 2018; Obrist et al. 2018), their exclusion herein should be interpreted not as diminished importance, but as an alternate focus. Instead, we examine extrinsic and intrinsic drivers that influence the routes of $\mathrm{Hg}$ exposure, and subsequently alter risks of $\mathrm{Hg}$ to human health and the health of organisms in the environment. The growing extent and intensity of some drivers will continue to influence key mechanisms associated with $\mathrm{Hg}$ exposure and bioaccumulation in both humans and other animals; thus, there is a critical need to understand these interactions to better predict changes in exposure trajectories and realized adverse health effects.

In this paper, we examine how specific extrinsic and intrinsic drivers that operate across multiple scales of organization (global, individual, and molecular) modulate mechanisms of $\mathrm{Hg}$ bioaccumulation in organisms and biomagnification through food webs, $\mathrm{Hg}$ exposure in humans, and $\mathrm{Hg}$ toxicity and health outcomes. Our goal is to integrate across disciplines that commonly are not linked, but nevertheless can exert cumulative influence on $\mathrm{Hg}$ health risks, in order to encourage scientific development of a more unified strategy for quantifying $\mathrm{Hg}$ risk during a time of rapid global change. As such, our objectives are to (1) examine the relationship between global change drivers and $\mathrm{Hg}$ bioaccumulation and biomagnification through ecosystems, (2) discuss key factors that influence human exposure to $\mathrm{MeHg}$ and inorganic $\mathrm{Hg}$, and (3) summarize interactive factors that can modulate toxic responses to $\mathrm{Hg}$ in wildlife and humans. This approach explicitly incorporates ecological, socioeconomic, and physiological factors to assist with quantifying the effectiveness of $\mathrm{Hg}$-reduction efforts on health outcomes and ecological risk. We address these objectives within a conceptual framework based upon pathways of $\mathrm{Hg}$ cycling through the ecosphere (Fig. 1), and within three key domains of ecological and human health risk. Domain 1 represents the extrinsic global change drivers that influence $\mathrm{MeHg}$ bioaccumulation and biomagnification through food webs. Domain 2 describes the global extrinsic drivers, and individual- and molecular-level intrinsic drivers that influence human exposure to both $\mathrm{MeHg}$ and inorganic $\mathrm{Hg}$, as well as how these drivers interact with those of Domain 1 to modulate $\mathrm{Hg}$ exposure through the human consumption of $\mathrm{Hg}$-contaminated foods. Domain 3 comprises the extrinsic and intrinsic drivers across a range of scales that influence the adverse effects of both $\mathrm{MeHg}$ and inorganic $\mathrm{Hg}$ in human and ecological health endpoints, and how they interact with the global change drivers described in Domains 1 and 2.

\section{DOMAIN 1: EXTRINSIC GLOBAL CHANGE DRIVERS THAT INFLUENCE METHYLMERCURY BIOACCUMULATION AND BIOMAGNIFICATION IN FOOD WEBS}

The unprecedented rate of human-induced changes in hydrology, land use, invasive species, and climate is 


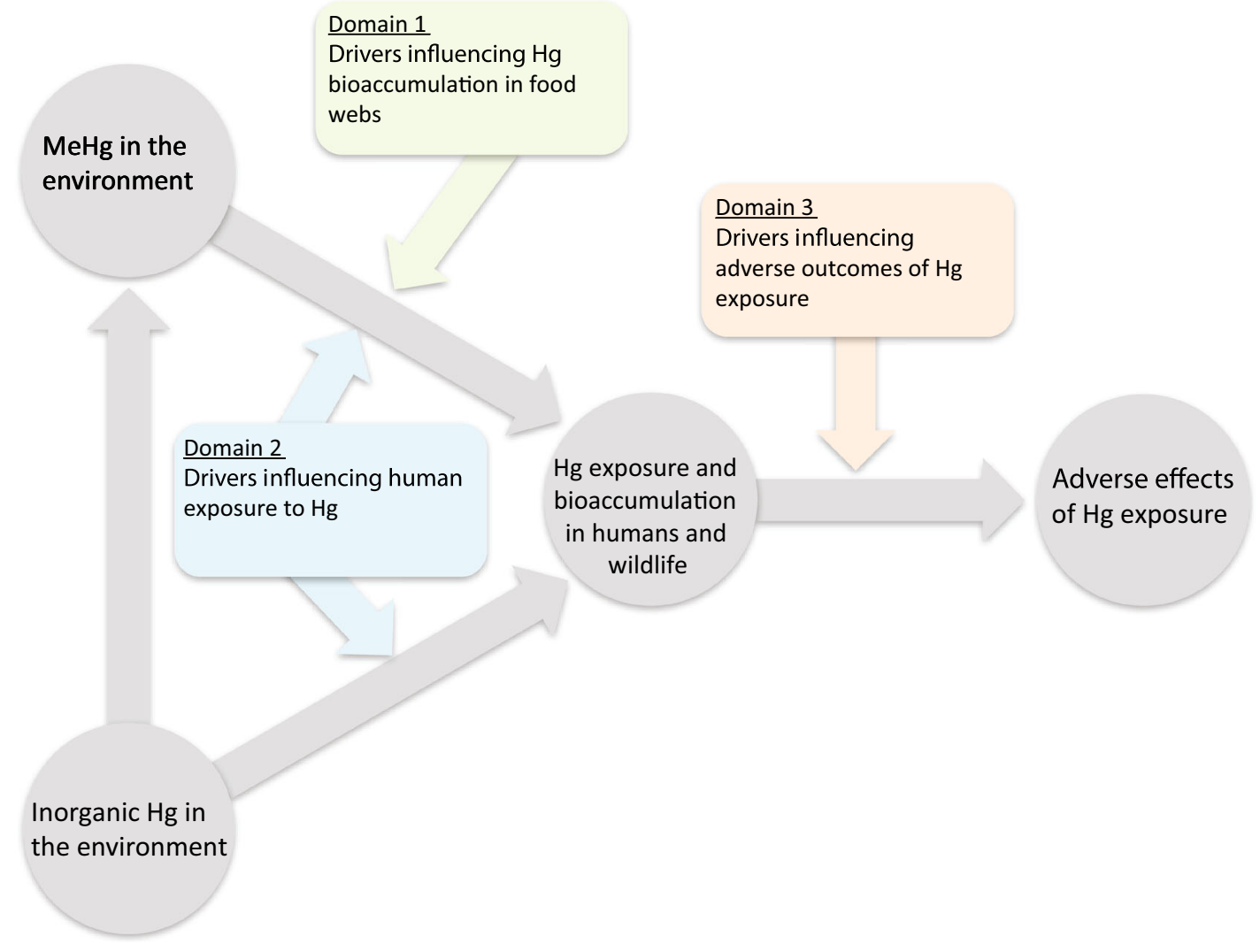

Fig. 1 Conceptual model of mercury (Hg) pathways through the ecosphere, and the domains of drivers that influence the risk of Hg exposure and related adverse health effects. The gray arrows represent the combined physical, chemical, and biological processes that influence movement from one category to another, and the domains represent key drivers that interact with those processes to influence outcomes in the receiving categories. Global extrinsic drivers affecting methylmercury $(\mathrm{MeHg})$ bioaccumulation in Domain 1 include hydrologic alteration, land-use change, invasive species, and climate change (see Fig. 2). Global extrinsic drivers that influence human exposure to inorganic $\mathrm{Hg}$ and $\mathrm{MeHg}$ in Domain 2 include changes in socioeconomic aspects of subsistence and luxury fish consumption and ASGM, whereas individual- and molecularlevel intrinsic drivers within this domain include genetic variability and gastrointestinal assimilation (see Fig. 3). Extrinsic and intrinsic drivers modulating adverse health outcomes of $\mathrm{MeHg}$ and inorganic $\mathrm{Hg}$ exposure in humans and other animals in Domain 3 include exposure to pathogens and infectious disease, and variations in nutrients and co-contaminants, the microbiome, and genetics

altering ecosystem processes on a global scale, including the distributions and interactions of species across terrestrial, freshwater, and marine habitats (Vitousek 1994; Hooper et al. 2012). Ecosystems respond to these extrinsic drivers in many ways, including through changes in food web structure and ecosystem energetics (Petchey et al. 1999; Baxter et al. 2004; Woodward et al. 2010), which influence $\mathrm{MeHg}$ bioaccumulation in food webs and subsequent dietary exposure to humans.

Herein, we identify four key ecological mechanisms that underlie changes in $\mathrm{MeHg}$ bioaccumulation through their effects on $\mathrm{MeHg}$ entry at the base of the food web, trophic transfer and biomagnification of $\mathrm{MeHg}$ through food webs, and toxicokinetics of $\mathrm{MeHg}$ within organisms. These mechanisms include (1) primary productivity, (2) habitat use, (3) bioenergetics, and (4) food web structure. Although there are some inherent overlaps among these mechanisms (e.g., hydrology dictates the available habitat, which can alter food web structure, etc.), their unique influences on $\mathrm{MeHg}$ bioaccumulation, biomagnification, and exposure warrant separate discussions. We then examine how each of these mechanisms can modulate (confound, moderate, or mediate) $\mathrm{MeHg}$ bioaccumulation and biomagnification when influenced by widespread global change drivers (Fig. 2). The extrinsic drivers considered in this domain are (1) hydrologic alteration, (2) landuse change (and associated changes to nitrogen cycling), and (3) invasive species. In addition, each of these extrinsic drivers occur within the context of (4) climate change, which modulates many aspects of the other drivers of global change. For each extrinsic driver presented below, we discuss its respective influences on one of the four mechanisms of bioaccumulation drawing support from the literature. 


\section{Global Change Drivers}

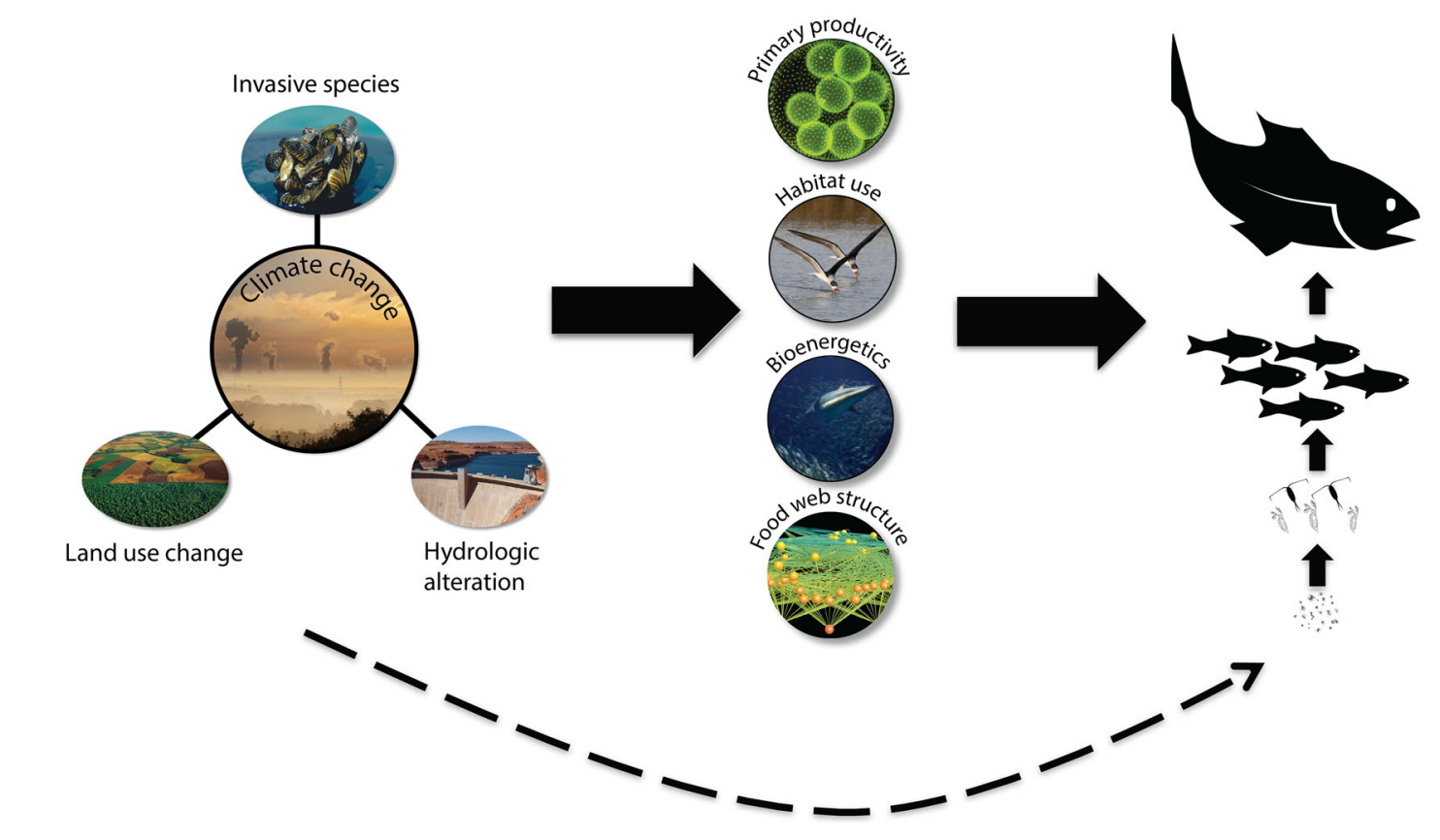

Mechanisms underlying

Bioaccumulation

\section{MeHg Bioaccumulation and Biomagnification}

Fig. 2 Major extrinsic drivers of global change (hydrologic alteration, land use change, invasive species, and climate change) indirectly (dashed arrow) influence methylmercury (MeHg) bioaccumulation and biomagnification through their direct effects (solid arrow) on key ecological mechanisms underlying $\mathrm{MeHg}$ bioaccumulation (primary productivity, habitat use, bioenergetics, and food web structure)

\section{Hydrologic alteration}

Hydrologic alteration is a defining characteristic of the Anthropocene and a major component of global change (Rosenberg et al. 2000). Dam, levee, and canal construction, wetland draining, and restriction of tidal exchange have fundamentally transformed the global water cycle, altering the ecology of freshwater ecosystems (Sahagian 2000), adjacent terrestrial riparian habitats (Poff et al. 2007), and receiving estuaries (Herbert et al. 2015). Globally, approximately 800,000 dams regulate over half of the world's river systems (Friedl and Wuest 2002; Nilsson 2005). These dams obstruct an estimated twothirds of freshwater flowing to the oceans (Nilsson and Berggren 2000), and redirect approximately $50 \%$ of the planet's accessible freshwater runoff for human use (Postel et al. 1996). Although dam construction has slowed since the 1970s, human population growth and economic development continue to drive a nearly exponential increase in global water use (Vorosmarty and Sahagian 2000). As a result, ongoing management of hydrology through reservoir operations, wetland restoration and management, and agricultural use maintains the global extent of continued hydrologic alteration, particularly in developing regions of the world (Janse et al. 2015). In particular, recent inventories suggest that small ponds created for agriculture and livestock purposes represent a substantial, previously unappreciated, and growing component of freshwater habitats (Downing et al. 2006), and they are disproportionately important for biogeochemical processes and as aquatic habitats for diverse organisms (Downing 2010).

Aquatic ecosystem functions are profoundly influenced by hydrologic alteration, resulting in changes to habitat connectivity and quality, community composition, and energy flow through ecosystems (Vorosmarty et al. 2000). Dams fragment riverine habitats (Rosenberg et al. 2000), alter water temperatures, and homogenize variation in discharge (Sabo et al. 2010). These physical and chemical changes manifest as ecological outcomes such as enhanced invasion of non-native species (Havel et al. 2005), community shifts from fluvial specialists to habitat generalists (Haxton and Findlay 2009), and increased food chain length (Sabo et al. 2010). The impacts of wetland loss on biodiversity and ecological function have been thoroughly described (Zedler and Kercher 2005), but even restored wetlands that are hydrologically managed to mirror predisturbance features exhibit both structural and functional biological degradation (Moreno-Mateos et al. 2012). Thus, many of the effects of hydrologic alteration are directly 
tied to the four key mechanisms of $\mathrm{Hg}$ bioaccumulation: primary productivity, habitat use, bioenergetics, and food web structure. The extent and magnitude of hydrologic alteration suggests that it may have a potentially significant impact on $\mathrm{Hg}$ bioaccumulation and biomagnification through food webs.

Fish and wildlife exposure to $\mathrm{MeHg}$ inherently differs among waterbody and habitat types (Ackerman et al. 2016; Eagles-Smith et al. 2016a) because hydrology influences the biogeochemical processes associated with $\mathrm{MeHg}$ production, as well as habitat availability and use, food web structure, and bioenergetics. As a result, hydrologic alteration is arguably among the most well-studied global change drivers of altered $\mathrm{MeHg}$ bioaccumulation in aquatic food webs. Reservoirs in particular have been associated with elevated $\mathrm{MeHg}$ bioaccumulation. Methylmercury concentrations in reservoir fish are between 1.4 to several fold higher than concentrations in fish from natural lakes (Kamman et al. 2005; Bodaly et al. 2007; Monson et al. 2011; Willacker et al. 2016), and the differences are particularly apparent in newly inundated reservoirs where rapid post-impoundment increases in $\mathrm{MeHg}$ concentrations occur through aquatic food webs. Studies in Scandinavia (Porvari 1998), North America (Willacker et al. 2016), Europe (Kruzikova et al. 2011), South America (Hylander et al. 2006), and Asia (Li et al. 2013) have all shown that total $\mathrm{Hg}$ and $\mathrm{MeHg}$ concentrations in aquatic food web components increased 3- to 30-fold within a few years after reservoir creation, with the magnitude of increases tied to amount of flooded area relative to reservoir surface area (Bodaly et al. 2007). Fish MeHg concentrations reached their maximum levels 2-14 years after impoundment across 8 hydroelectric reservoirs in Canada (Bodaly et al. 2007), and an average of 3 years after impoundment across dozens of reservoirs throughout western North America (Willacker et al. 2016). Because MeHg concentrations and reproductive risk in piscivorous birds are highly correlated with $\mathrm{MeHg}$ concentrations in prey fish (Evers et al. 2008; Ackerman et al. 2015), waterbird species attracted to reservoirs or their discharge waters may be at particularly high risk to $\mathrm{MeHg}$ exposure in the years following reservoir creation. Reservoir creation can also enhance the magnitude of aquatic invertebrate emergence, increasing the available biomass of $\mathrm{Hg}$-contaminated prey and associated $\mathrm{Hg}$ exposure in insectivorous birds (Gerrard and $\mathrm{St}$ Louis 2001), providing biologically mediated subsidies to adjacent terrestrial habitats. The pulse in $\mathrm{MeHg}$ bioaccumulation through food webs does not occur in all newly impounded reservoirs however ( $\mathrm{Li}$ et al. 2015), and although the mechanisms are not well understood, evidence suggests that food chain length in reservoirs may be an important regulating factor (Razavi et al. 2014; Ouedraogo et al. 2015).
Mercury concentrations in reservoir fish (and likely other taxa) eventually return to near pre-impoundment levels, although it can take several decades (French et al. 1998; Bodaly et al. 2007; Willacker et al. 2016) with rates of decline ranging between 0.5 and $3.9 \%$ per year (Green et al. 2016). However, both reservoir management and hydrologic structure can confound any return to background concentrations. Water level management, specifically the magnitude of between-year changes in maximum water levels, is linearly correlated with fish $\mathrm{Hg}$ concentrations in subsequent years (Sorensen et al. 2005; Larson et al. 2014; Willacker et al. 2016) and has been associated with up to a threefold difference in fish $\mathrm{Hg}$ concentrations from reservoirs with low versus high proportional changes in maximum water levels (Willacker et al. 2016). Water column stratification also influences food web $\mathrm{Hg}$ bioaccumulation, both within reservoirs (Slotton et al. 1995; Perron et al. 2014), as well as downstream environments. Elevated $\mathrm{Hg}$ concentrations in food webs can extend up to $200 \mathrm{~km}$ below dams (Kasper et al. 2014).

The influence of hydrologic alteration on $\mathrm{Hg}$ dynamics within food webs extends to other water bodies. For example, fish $\mathrm{Hg}$ concentrations have been shown to be highest in wetlands with the greatest degree of water level fluctuation (Snodgrass et al. 2000; Eagles-Smith and Ackerman 2014), and white ibis chick Hg concentrations were directly tied to water level fluctuation rates in the Florida Everglades (Herring et al. 2013). Highly managed, small agricultural ponds, represent and important habitat in semi-arid regions with limited aquatic habitat availability (Chumchal and Drenner 2015), where invertebrate $\mathrm{MeHg}$ flux to terrestrial environments differed among ponds with varying water management and presence or absence of fish (Henderson et al. 2012; Tweedy et al. 2013). Further, river geomorphology can influence aquatic-terrestrial Hg transfer through the collective effects on emergent insect body burdens and aquatic insect community composition (Sullivan et al. 2016).

\section{Land-use change}

Rapid and irreversible conversion of lands for the production of food, extraction of resources, and urbanization is occurring globally. These alterations have disturbed natural hydrologic, geochemical, and biological processes due to the production and discharge of wastes, impervious surfaces of cities, conversion of forests to pastures for livestock and crop monocultures, and addition of fertilizers and pesticides to increase food production (Tilman et al. 2001). Widespread changes to terrestrial systems and unsustainable resource consumption by a rapidly growing population has resulted in global shifts in the nitrogen cycle (Vitousek 1994), unprecedented losses in biodiversity (Phalan et al. 
2011), pervasive eutrophication of aquatic ecosystems (Carpenter and Bennett 2011), and impacts on regional and global climate (Vitousek 1994; IPCC 2014).

These broad-scale changes to the landscape are also altering the fate of $\mathrm{Hg}$ through their effects on the structure and function of terrestrial and aquatic systems and the four key mechanisms governing $\mathrm{MeHg}$ bioaccumulation (primary productivity, habitat use, bioenergetics, and food web structure). For example, direct toxicity, changes in nutrient flow, and habitat loss can each result in losses of sensitive species and biodiversity, which affects food web structure (e.g., urban effluents (Wenger et al. 2009; Holeton et al. 2011); agricultural pesticides and fertilizers; forestry, (Richardson and Beraud 2014)). The growth rates and bioenergetics of species shift as a result of changes in food supply, competition, and predation (Brinkmann and Rasmussen 2010). Losses in forest cover and permeable lands alter the timing and magnitude of water flow from terrestrial to aquatic systems (Sampaio da Silva et al. 2009; Wenger et al. 2009). Finally, the primary productivity of ecosystems from heavy reliance on fertilizers is increasing the availability of limiting nutrients to terrestrial and aquatic vegetation (Vitousek et al. 1997; Carpenter et al. 1998).

Of the four key mechanisms, alterations in primary productivity and its effects on $\mathrm{MeHg}$ in consumers is arguably one of the better studied, but controversies remain over the resultant net effects on $\mathrm{Hg}$ uptake in biota. Increases in the biomass of primary producers may dilute $\mathrm{MeHg}$ concentrations in the base of the food web [algae (Pickhardt et al. 2002; Perron et al. 2014)] and subsequently in predators (e.g., zooplankton (Chen and Folt 2005), fish (Larsson et al. 1992; Kidd et al. 1999; Essington and Houser 2003)). Alternatively, $\mathrm{MeHg}$ production may be enhanced due to a greater abundance of primary producers (Lepak et al. 2015), thereby facilitating in situ Hg methylation (Mauro et al. 2002; Paranjape and Hall 2017). Increases in the primary productivity of artificial streams by several orders of magnitude led to comparable declines in $\mathrm{MeHg}$ concentrations of both algae and algal consumers, supporting the biodilution hypothesis (Walters et al. 2015), whereas other experimental evidence showed either no effect or increased $\mathrm{MeHg}$ concentrations resulting from enhanced primary production (Rudd and Turner 1983; Jones et al. 2013). In addition, a review of several case studies examining fish $\mathrm{Hg}$ concentrations across a gradient of nutrient loading to coastal waters found examples that both supported and challenged the biodilution hypothesis (Driscoll et al. 2012). Although contradictory, the experimental and field evidence clearly shows that primary productivity can both reduce and enhance $\mathrm{MeHg}$ bioaccumulation, and it is important to resolve the contexts in which each of these responses are more likely to occur. Agricultural runoff and municipal wastewaters are the largest contributors to eutrophication of freshwater and marine coastal systems, yet there are surprisingly few studies of their impacts on $\mathrm{Hg}$ cycling in aquatic ecosystems and in the terrestrial landscape upon which pesticides, wastewater biosolids, fertilizers, and manures are applied.

\section{Invasive and introduced species}

Long distance transportation and globalization have resulted in the intentional and unintentional transport of microbes, flora, and fauna around the world (Pimentel et al. 2000; Richardson et al. 2000). Non-native species that become established in new localities can outcompete or prey upon native species, introduce diseases, alter critical ecosystem functions, influence water and food supplies for humans, and cause extraordinary economic losses (Mack et al. 2000; Pimentel et al. 2000; Richardson et al. 2000; Pimentel et al. 2001, 2005). As a result, invasive species are now widely recognized as one of the greatest anthropogenic challenges facing the planet (Mack et al. 2000; Pimentel et al. 2005).

Invasive invertebrates, plants, and animals can upend ecosystem-level processes, alter food web composition, and influence the health and survival of native organisms in the receiving ecosystem. For example, invasive plants can differ from native plants in their physiology and phenology, sometimes producing striking differences in biomass, primary productivity, rhizosphere activity, and fundamental alterations to nutrient and water cycles (Ehrenfeld 2003; Gentes et al. 2013). Invasive invertebrates such as zebra mussels can overwhelm aquatic systems and cause wholesale changes in phytoplankton and zooplankton community structure, driving cascading effects on the diets and growth of fish and other aquatic animals (McNickle et al. 2006). Invasive vertebrates, such as Burmese pythons, brown tree snakes, cane toads, and fish, can alter the growth rates and population densities of native vertebrates, and in extreme cases can eliminate native species altogether through predation, pathogen transmission, resource competition, toxicity, and/or competitive exclusion (Vander Zanden et al. 1999; Phillips et al. 2003; Wiles et al. 2003; Dorcas et al. 2012; Willson 2017). Importantly, the effects of invasive species on ecosystem processes and food web structure can vary based on the characteristics of the recipient ecosystem, suggesting that a variety of sitespecific factors influence the ecological outcomes of species introductions (Ehrenfeld 2003; Occhipinti-Ambrogi and Savini 2003; Vander Zanden et al. 2003; Swanson et al. 2006).

Despite the profound impacts that invasive species have on ecological systems, surprisingly little is known about how they influence the dynamics of co-occurring anthropogenic pollutants such as $\mathrm{MeHg}$. One mechanism by 
which invasive species may influence movement of $\mathrm{MeHg}$ through food webs is by altering hydrology, biogeochemistry, and microbial processes that control site-specific $\mathrm{MeHg}$ production, facilitating subsequent bioaccumulation. For example, saltcedar (Tamarix spp.) introductions across the western U.S. may have modified the hydrology of reservoirs, streams, and floodplains due to evapotranspiration (reviewed in Shafroth et al. (2005)). Likewise, the highly invasive common reed (Phragmites australis) forms dense monocultures in both freshwater and brackish systems, excluding other plant and animal species, reducing light penetration, and modifying decomposition rates and nutrient cycling (Meyerson et al. 2000). Similarly, introduced aquatic macrophytes can overwhelm aquatic habitats, particularly under eutrophic conditions. The macrophytic rhizosphere is critical to $\mathrm{Hg}$ methylation, and thus has the potential to increase bioavailability to local fauna (Gentes et al. 2013). Although the impact of these nonnative plant introductions on $\mathrm{Hg}$ accumulation in resident food webs have not been considered, these examples illustrate the broad ecological changes that invasive species can cause, and the high probability that these alterations could influence $\mathrm{MeHg}$ dynamics.

Relatively few studies have directly considered how invasive species influence bioaccumulation of $\mathrm{Hg}$ in receiving ecosystems, and most of these have focused on changes in feeding ecology and trophic structure due to invasions or introductions. Because where an organism feeds can influence $\mathrm{MeHg}$ exposure and subsequent $\mathrm{MeHg}$ bioaccumulation (Power et al. 2002; Karimi et al. 2016a), one process that invasive species could affect, that would in turn modify $\mathrm{MeHg}$ fate, is changes to the foraging habitat. Indeed, threadfin shad (Dorosoma petenense) introduced to a lake in California, USA outcompeted resident planktivorous species for zooplankton, causing resident fishes to shift from pelagic to benthic prey. The dietary shift resulted in a $50 \%$ increase in $\mathrm{Hg}$ concentrations of resident planktivorous fish (Eagles-Smith et al. 2008). Alternatively, introduced species can alter the length of trophic pathways and thus influence $\mathrm{Hg}$ dynamics within food webs. For example, introduced rainbow smelt (Osmerus mordax) in Canadian lakes feed at slightly higher trophic positions than native forage fish and could thus theoretically expose predatory fish to higher concentrations of dietary $\mathrm{Hg}$. However, support for this hypothesis is mixed (Evans and Loftus 1987; Franzin et al. 1994; Vander Zanden and Rasmussen 1996; Hrabik et al. 1998; Johnston et al. 2003), possibly because localized water chemistry and rapid growth rates of fish (i.e., growth dilution of $\mathrm{Hg}$ ) may offset relatively fine-scale changes in trophic position (Swanson et al. 2006).

In light of the diverse effects that introduced species can have on ecological systems and their widespread and growing presence, considerable research is needed to understand how invasive species influence $\mathrm{MeHg}$ bioaccumulation. The examples above suggest this area continues to emerge as a key aspect of the overlap between invasive species and $\mathrm{MeHg}$ bioaccumulation through food webs. More data are needed to understand the conditions under which invasive species are most likely to influence $\mathrm{MeHg}$ bioaccumulation in ecosystems by altering methylation processes, food web structure, feeding ecology, hydrology, and bioenergetics of resident communities. Baseline tissue $\mathrm{Hg}$ concentrations will be essential to elucidate pre- and post-invasion changes to $\mathrm{MeHg}$ dynamics, and studies will need to consider site-specific ecological factors that may influence $\mathrm{MeHg}$ bioaccumulation resulting from invasions.

\section{Climate change}

Whereas hydrologic alteration, land-use change, and invasive species are examples of localized drivers occurring globally, climate change is a global phenomenon with both global and localized impacts. As a result, it both directly and indirectly influences the four key mechanisms of $\mathrm{MeHg}$ bioaccumulation (primary productivity, habitat use, bioenergetics, and food web structure). It directly influences each mechanism by changing the physical and chemical properties of the environment, which triggers ecological responses. It also indirectly influences each mechanism of $\mathrm{MeHg}$ bioaccumulation because climate change motivates adaptation in land use (Dale 1997; Gao and Liu 2011) and water storage and conveyance (Christensen et al. 2004; Olden and Naiman 2010), while also creating expanded opportunities for non-native species invasions (Rahel and Olden 2008). Thus, climate change indirectly influences $\mathrm{MeHg}$ bioaccumulation and biomagnification through alterations in primary productivity, and food web structure, as well as bioenergetics.

Because diet is the primary $\mathrm{MeHg}$ exposure route, $\mathrm{MeHg}$ follows energetic pathways through food webs and is tied to an organism's energy expenditure, acquisition, and storage. The link between $\mathrm{MeHg}$ bioaccumulation and bioenergetics is most commonly exhibited through growth dilution, whereby $\mathrm{Hg}$ concentrations are lower in faster growing individuals with higher growth efficiency than those that grow more slowly and have lower growth efficiency. This process has been demonstrated in both fish (Ward et al. 2010) and birds (Ackerman et al. 2011), and is commonly visible in the negative relationship between $\mathrm{Hg}$ concentrations and body condition (Eagles-Smith et al. 2016b; Baumann et al. 2017). Growth efficiency and associated bioenergetics can be influenced by either changes in basal metabolic rate (Dijkstra et al. 2013), activity costs, or food quality (Lepak et al. 2012; Johnson et al. 2015; Karimi et al. 2016a). Thus, environmental conditions that influence these factors, such 
as temperature, can also modulate $\mathrm{MeHg}$ bioaccumulation and biomagnification. For example, global average sea surface temperature has increased by $0.11^{\circ} \mathrm{C}$ per decade between 1971 and 2010, and is projected to further increase by $1-3{ }^{\circ} \mathrm{C}$ over the next 50 years (IPCC 2014). Many freshwater systems may endure even higher temperature increases (Magnuson et al. 1997). Microcosm and experimental laboratory studies have shown that $\mathrm{MeHg}$ concentrations in killifish increased substantially over a 3 and $7{ }^{\circ} \mathrm{C}$ temperature gradient, respectively, and changes in concentrations were largely due to increased food consumption to maintain the higher basal metabolic rate associated with warmer water temperatures (Dijkstra et al. 2013). Metabolic allometric scaling theory predicts that higher temperatures and associated metabolic rates will also induce community shifts toward smaller body sizes, which has further trickledown ramifications for ecosystem metabolic processes (Woodward et al. 2010). Among those relevant to $\mathrm{MeHg}$ bioaccumulation are changes in food quality and energy density (Ficke et al. 2007, Atcheson et al. 2012). Lower energy content in food requires higher consumption rates to meet metabolic needs. Thus, even if $\mathrm{MeHg}$ concentrations in prey remain unchanged, $\mathrm{MeHg}$ exposure in consumers would increase as they attempt to meet basal energy requirements. These processes have important implications for evaluating the effectiveness of global $\mathrm{Hg}$ reductions because changes in $\mathrm{Hg}$ concentrations of sentinel species may respond to both changes in $\mathrm{Hg}$ releases as well as extrinsic drivers such as climate change. As a result, strategies need to be developed that incorporate the role of these extrinsic drivers into models of $\mathrm{MeHg}$ bioaccumulation.

Cumulatively, the four extrinsic global change drivers described above (hydrologic alteration, land-use change, invasive species, and climate change) will continue to change patterns of $\mathrm{MeHg}$ bioaccumulation and biomagnification in complex ways. The contexts in which these drivers act is important to define in order to begin incorporating their effects into risk determination because their influence on $\mathrm{MeHg}$ bioaccumulation patterns will ultimately affect $\mathrm{MeHg}$ concentrations in fish, which is the primary source of $\mathrm{MeHg}$ to most humans.

\section{DOMAIN 2: GLOBAL EXTRINSIC AND INDIVIDUAL/MOLECULAR-LEVEL INTRINSIC DRIVERS OF MERCURY EXPOSURE IN HUMANS}

Most human populations are exposed to $\mathrm{Hg}$ through the consumption of $\mathrm{MeHg}$-contaminated fish, shellfish, and marine mammals (Sheehan et al. 2014), although rice has also emerged as a major $\mathrm{MeHg}$ vector in some populations (Zhang et al. 2010; Hsu-Kim et al. 2018). Human exposure to elemental or inorganic $\mathrm{Hg}$ can occur from sources present in certain occupational settings and contaminated sites as well as from $\mathrm{Hg}$-containing products. As a result, approaches to minimize $\mathrm{Hg}$ exposure in humans encounter inherent conflicts because many of these $\mathrm{Hg}$ sources also have great value for public health, such as seafood consumption and the use of dental amalgams. Limiting exposure to these and other potential $\mathrm{Hg}$ sources can thus have negative health implications. Although alternatives to these $\mathrm{Hg}$ sources exist (e.g., $\mathrm{Hg}$-free dental restoration options and low-Hg fish choices), they are often limited to more economically developed nations or would result in the elimination of culturally important food items. Thus, predicting the health risks associated with $\mathrm{MeHg}$ and inorganic $\mathrm{Hg}$ exposure in human populations is not only complicated by the global change drivers discussed in Domain 1 that influence $\mathrm{Hg}$ concentrations in food items that humans consume, but also by global economic and societal drivers.

Intrinsic drivers such as genetic variability also influence human exposure to $\mathrm{Hg}$, as well as the relationship between actual $\mathrm{Hg}$ exposure and the commonly accepted biomarkers that are used to estimate exposure in humans (i.e., blood $\mathrm{Hg}$ concentration reflects exposures to both organic and inorganic $\mathrm{Hg}$, whereas $\mathrm{Hg}$ concentrations in hair and urine reflect exposures to organic and inorganic $\mathrm{Hg}$, respectively). This is an important aspect of understanding human exposure to $\mathrm{Hg}$ because standard risk assessments often assume a constant and linear relationship between $\mathrm{Hg}$ exposure and different biomarker levels, despite evidence of tremendous variability in those relationships (Canuel et al. 2006). The potential lack of predictable concordance between $\mathrm{MeHg}$ or inorganic $\mathrm{Hg}$ exposure in humans and common biomarkers of exposure can have significant implications for the use of these surveillance and monitoring tools in risk assessments of $\mathrm{Hg}$ exposure, as well as epidemiological studies of the potential health effects of $\mathrm{Hg}$ exposure.

In this section, we examine the key drivers associated with $\mathrm{Hg}$ exposure in humans that scale from individualand molecular-level drivers, such as genetic variability, to global drivers, such as socioeconomics (Fig. 3). Specifically, we describe key socioeconomic factors that influence $\mathrm{Hg}$ exposure patterns in different cultures and populations as well as extrinsic and intrinsic individual-level drivers that may confound, moderate, or mediate $\mathrm{Hg}$ exposure and assimilation in humans.

\section{Global socioeconomic drivers: Extrinsic}

\section{Subsistence fishing, high-end economic fish, and rice consumption}

Socioeconomic status is a common factor that drives disparities in $\mathrm{Hg}$ exposure among communities (Nriagu et al. 

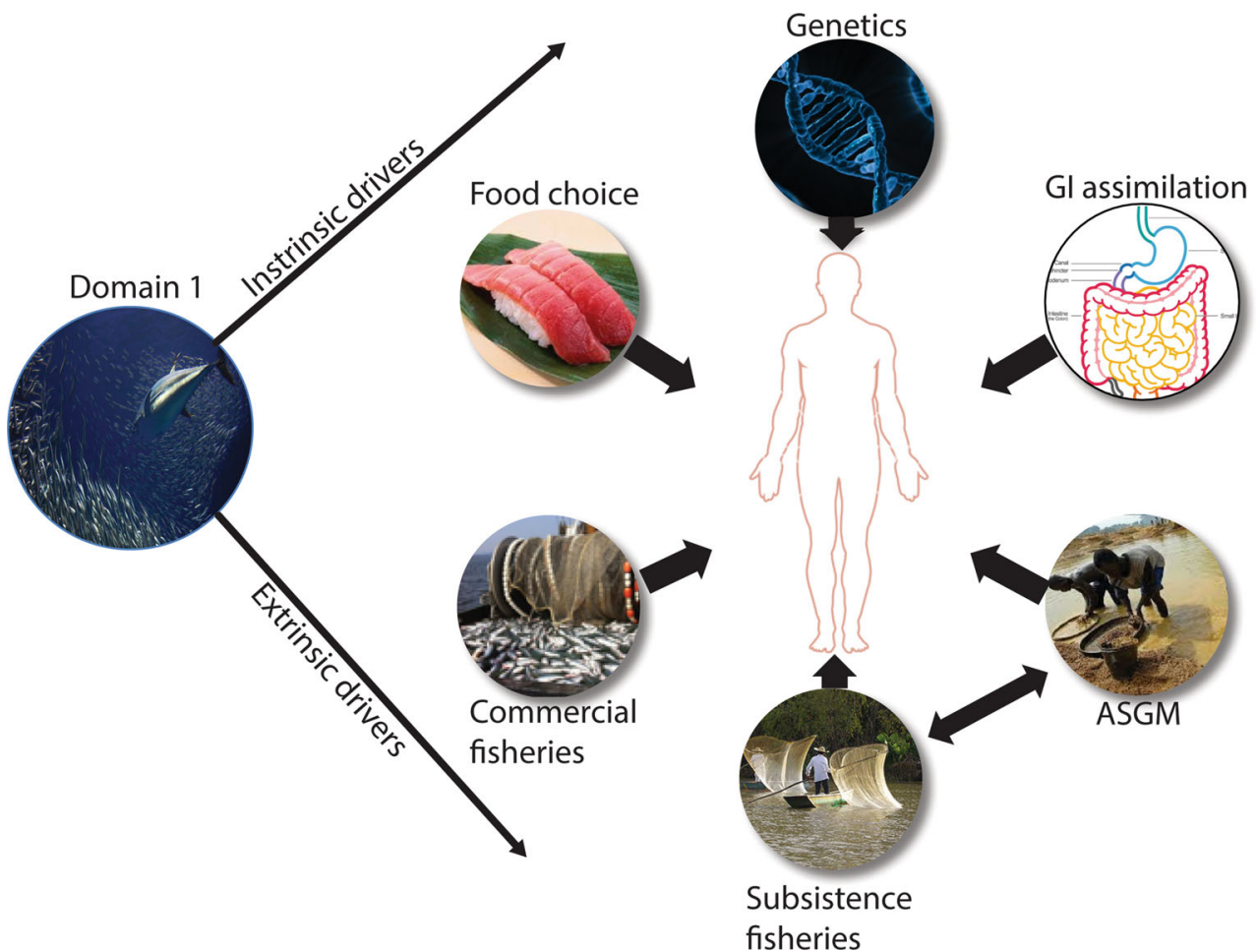

Fig. 3 Domain 2 represents extrinsic and intrinsic drivers that influence mercury $(\mathrm{Hg})$ exposure in human populations. Domain 2 is influenced by the extrinsic drivers discussed in Domain 1 as they relate to human exposure to methylmercury through the consumption of $\mathrm{Hg}$-contaminated fish

2012). The relationships between socioeconomic status and $\mathrm{MeHg}$ exposure in humans is nonlinear and is complicated by the numerous pathways of exposure. Both poverty and wealth portend $\mathrm{Hg}$ exposure risk for many communities, creating challenges to the development of policies to reduce risk, and to predict how risks will change with shifts in global trade and economic development. In industrialized nations, lower income urban anglers, especially minority and immigrant populations, can be at particularly high risk of $\mathrm{Hg}$ exposure because they are more likely to consume self-caught rather than store-bought fish, and often these anglers target predatory species with the highest Hg concentrations (Nriagu et al. 2012; Lauber et al. 2017). Risks of exposure to $\mathrm{Hg}$ and other environmental contaminants are also elevated for these populations because they are less likely to trust and/or adhere to fish consumption advisories (Perez et al. 2012; Niederdeppe et al. 2015). At the other end of the spectrum, individuals who more frequently consume tuna steak or swordfish, typically those in higher socioeconomic populations, are also at increased risk of elevated $\mathrm{Hg}$ exposures (Hightower and Moore 2003; Mahaffey et al. 2009; Karimi et al. 2014; Goodrich et al. 2016). A third group includes Indigenous populations and rural subsistence fishing communities in resource-limited regions (Chan et al. 2003). Coastal Indigenous groups represent approximately $0.4 \%$ of the global human population, but they consume an amount of fish equal to $2 \%$ of the global commercial catch (CisnerosMontemayor et al. 2016), and their average per-capita consumption of seafood is 15 times higher than national averages (Cisneros-Montemayor et al. 2016). Some of the most impacted coastal groups are circumpolar Inuit populations, who have among the world's highest $\mathrm{MeHg}$ exposures due to their particularly high reliance on marine mammals and fish consumption, although rapid changes in climate, food availability, and dietary choices are complicating risk assessments (AMAP 2015). Often, fish consumption in many of these communities not only serves as a critical source of protein, but also has a strong cultural connection, thus presenting unique social justice and risk communication complications. Encouraging these communities to consume alternative fish species with lower $\mathrm{Hg}$ concentrations may benefit their health, but jeopardize key aspects of their heritage, whereas maintaining traditional practices may preserve heritage, but have negative health consequences. In addition, recent evidence suggests that the majority of $\mathrm{MeHg}$ exposure in some rural Asian populations occurs through rice consumption (Zhang et al. 2010). The magnitude and extent of $\mathrm{MeHg}$ exposure risk through rice is not yet clear, but appears particularly acute in rural areas with $\mathrm{Hg}$-contaminated soils (Feng et al. 2008). 
As industrial development continues and economies of different countries shift in response to globalization, population growth, and resource availability, the relative $\mathrm{Hg}$ exposure risk in distinctive populations is likely to change in response. Similarly, continued exploitation of fisheries and "fishing down" marine food webs (Pauly et al. 1998; Essington et al. 2006; Baum and Worm 2009) is expected to influence $\mathrm{MeHg}$ concentrations in common market fish, thereby changing the exposure risk of the regions in which those species are commonly sold (see Box 1).

\section{Box 1 Global change and $\mathrm{Hg}$ exposure through fish consumption}

Worldwide the most important $\mathrm{MeHg}$ source to human populations is the consumption of contaminated seafood. The amount of $\mathrm{Hg}$ that ends up in commercially available seafood depends on a range of environmental factors such as atmospheric loading rates, ecosystem-specific biogeochemical properties, and food web structure (Selin et al. 2010; Sunderland and Selin 2013), as well as socioeconomic factors such as market supply and demand. Of all seafood, $\mathrm{Hg}$ from tuna from the commercial market is often the most dominant source for human consumption in the U.S. (Sunderland 2007; Karimi et al. 2012), Japan (Nakagawa et al. 1997; Yamashita et al. 2005), and Mexico (Cantoral et al. 2017). Over the past few decades, the consumption of tuna sashimi has expanded from the Japanese market to a global one, contemporaneous with new distribution systems in which large supermarket and retailers are being favored over fish markets and auctions. Canned tuna production and demand continues to rise, with key markets being the U.S., the European Union, and Japan. However, as wealth increases elsewhere, these regions are also declining as a percentage of the world market.

The global demand and preferences for specific fish species has also had substantial effects on the composition and structure of marine food webs (Pauly et al. 2005; Daskalov et al. 2007). In particular, global markets for upper-trophic-level species has reduced the mean trophic level and average size of fish harvested over the past several decades (Pauly et al. 1998, 2005). Simultaneously, global demand to support the growing market for fish oil and fishmeal has resulted in substantial increases in the harvest of "forage fish" species that occupy lower trophic positions (Essington et al. 2006; McClanahan et al. 2015). These harvest-induced changes to marine food webs certainly have implications for $\mathrm{MeHg}$ concentrations in market fish and associated human $\mathrm{MeHg}$ exposure, but these relationships have not been thoroughly investigated. Finally, aquaculture production has increased dramatically over the last three decades, particularly in Asia (Jennings et al. 2016), and currently represents $44 \%$ of the total global seafood production (Lopes et al. 2017). Farmed seafood has been shown to contain substantially lower $\mathrm{Hg}$ concentrations than taxonomically related wild-caught seafood (Karimi et al. 2012), providing a mechanism for reducing $\mathrm{Hg}$ exposure in some consumers. However, the context-dependent implications of these trends are uncertain for future trajectories of $\mathrm{MeHg}$ exposure to different human populations. In addition, responses of fisheries to global change drivers, as discussed in Domain 1, represent a key area of uncertainty that is likely to be extremely consequential for reducing human exposure to $\mathrm{Hg}$.
Artisanal small-scale gold mining (ASGM) and mercury mining

Socioeconomic trends can also influence human exposure to inorganic $\mathrm{Hg}$, particularly from sources associated with ASGM. This mining is carried out in over 70 countries (mainly those with low- and middle-income economies) by approximately 10-15 million miners, including approximately 4-5 million women and children (UNEP 2013; WHO 2016). Within ASGM communities, $\mathrm{Hg}^{0}$ is used to amalgamate gold from processed ore, then the amalgam is subsequently heated to burn off the $\mathrm{Hg}$ as a vapor, leaving a concentrated gold ore. Annual Hg emissions from ASGM are estimated at 727 tonnes, making this the largest sector of $\mathrm{Hg}$ emissions, accounting for more than $35 \%$ of total global anthropogenic emissions of Hg (UNEP 2013). It has been argued that ASGM is a poverty-driven activity with pertinent micro- and macroeconomic drivers as well as push-pull factors (Hilson and Garforth 2012; Wilson et al. 2015). Biomonitoring surveys of ASGM workers and community members show that they have among the highest $\mathrm{Hg}$ exposures of any group worldwide (Gibb and O'Leary 2014; Basu et al. 2015b). This is not surprising considering the high amounts of $\mathrm{Hg}$ used in the practice, the limited use of personal protective equipment or $\mathrm{Hg}$-free or -reduction techniques, and the overall rudimentary nature of most ASGM sites. The Hg exposure risks are further exacerbated by the fact that most ASGM operations are informal (and illegal in many countries) and thus sit outside regulatory and public health support programs (see Box 2).

\section{Medical, personal care, and cultural use}

Although fish consumption and ASGM are the dominant drivers of $\mathrm{Hg}$ exposure to most humans, other sources such as medical and personal care products can be important contributors for specific subsets of individuals. Historically, $\mathrm{Hg}$ was used for therapeutic medical purposes such as treatment for syphilis and as a component in teething powders (Clarkson and Magos 2006). These uses have been phased out, but modern medical applications still exist. In particular, $\mathrm{Hg}$ continues to be used as a component of dental amalgams and vaccines. These uses have generated controversy because of the known toxicity of $\mathrm{Hg}$. The public health weight of evidence is somewhat equivocal, but generally has not pointed to adverse health outcomes associated with amalgams (Clarkson and Magos 2006) or vaccines (Stratton et al. 2001). However, developing biomarkers of $\mathrm{Hg}$ sensitivity and subtle adverse effects of $\mathrm{Hg}$ exposure (see Domain 3 ) may further inform this topic (Branco et al. 2017; Crowe et al. 2017; Dorea 2017; Modabbernia et al. 2017). Voluntary steps to reduce uses of $\mathrm{Hg}$ in medical applications have been taken by many producers and in many countries, but it still represents a 
Box 2 ASGM as an example of an extrinsic global driver of human $\mathrm{Hg}$ exposure

The prevalence and extent of ASGM is largely driven by local, community, and cultural factors, but global-scale drivers, such as economic market trends, are also important determinants. For example, sudden changes in the global price of gold correlated with the importation of $\mathrm{Hg}$ and the expansion of ASGM areas in Peru between 2003 and 2008 (Swenson et al. 2011). During this period, which included the global economic crash, the price of gold rose markedly and reported $\mathrm{Hg}$ imports into Peru increased by $42 \%$. Satellite imagery showed that rates of forest conversion to mining increased 6-fold during this time period. Combining all these data, the authors reported strong correlations among these covariates as shown in Fig. 4, providing a striking illustration of the importance of global economics as a driver of $\mathrm{Hg}$ use and ecological degradation in ASGM regions.

Similarly, ASGM gold production in Ghana increased 15 -fold between 1995 and 2014 in response to a roughly 6-fold increase in the price of gold. During that time frame, the number of ASGM miners in Ghana rose 33-fold, from approximately 30,000 in 1995 to 1 million in 2010, and forest cover decreased from 32.7 to $21.7 \%$. Although estimates of $\mathrm{Hg}$ imports are difficult to obtain, limited estimates indicate that they increased from $272 \mathrm{~kg} \mathrm{Hg}$ in 2010 , when approximately $21,000 \mathrm{~kg}$ of gold was produced, to $2015 \mathrm{~kg}$ of $\mathrm{Hg}$ imported in 2013 when more than $41,000 \mathrm{~kg}$ of gold was produced.

significant source of $\mathrm{Hg}$ to many populations and thus should to be considered in cumulative exposure assessments.

Cultural norms, traditions, and religious ceremonies are additional extrinsic drivers that can influence $\mathrm{Hg}$ exposure (particularly to $\mathrm{Hg}^{0}$ and $\mathrm{Hg}^{\mathrm{II}}$ ) in certain human populations. Application of Hg-containing skin-lightening creams to achieve desired physical appearances is a common practice in some populations, with prevalence rates as high as $50 \%$ in some countries (Dlova et al. 2015; Gbetoh and Amyot 2016; Lartey et al. 2017). Unregulated products often contain either $\mathrm{Hg}$ or calomel, or $\mathrm{Hg}$ is intentionally added by the user (Copan et al. 2015). Mercury exposure also occurs through certain ethno-medical and religious practices such as sprinkling elemental $\mathrm{Hg}$ on the floor of the home or burning it in candles to ward off evil spirits (Zayas and Ozuah 1996; Masur 2011). In 2005, a population-based study in New York, found that women from Dominican and Caribbean cultures had higher urine $\mathrm{Hg}$ levels than those from other cultural groups (McKelvey et al. 2011), and the increased concentrations correlated with both the use of $\mathrm{Hg}$-containing skin-lightening creams (as mentioned previously) and the use of elemental $\mathrm{Hg}$ in religious and ethnic practices. Similarly, another study of prenatal exposures to $\mathrm{Hg}$ in a U.S. population of predominately Caribbean immigrants found that high maternal urine $\mathrm{Hg}$ levels were associated with religious use of $\mathrm{Hg}$ during pregnancy, including candle burning and religious charms, while elevated cord blood $\mathrm{Hg}$ was associated with fish consumption during pregnancy (Geer et al. 2012). Of note, these studies of individuals from cultures with specific religious uses of $\mathrm{Hg}$ were conducted in the U.S.; while public health resources are available to these U.S. immigrants in order to reduce risks from $\mathrm{Hg}$ exposure, the founder populations in other countries may not have the same level of access to those types of resources. Thus, these published $\mathrm{Hg}$ exposure risks may be significantly higher in other countries (Johnson 1999; Riley et al. 2001; Newby et al. 2006).

\section{Individual- and molecular-level drivers: Intrinsic}

\section{Genetics}

Exposure biomarkers (e.g., blood, hair, or urine $\mathrm{Hg}$ concentrations) are important tools for monitoring and

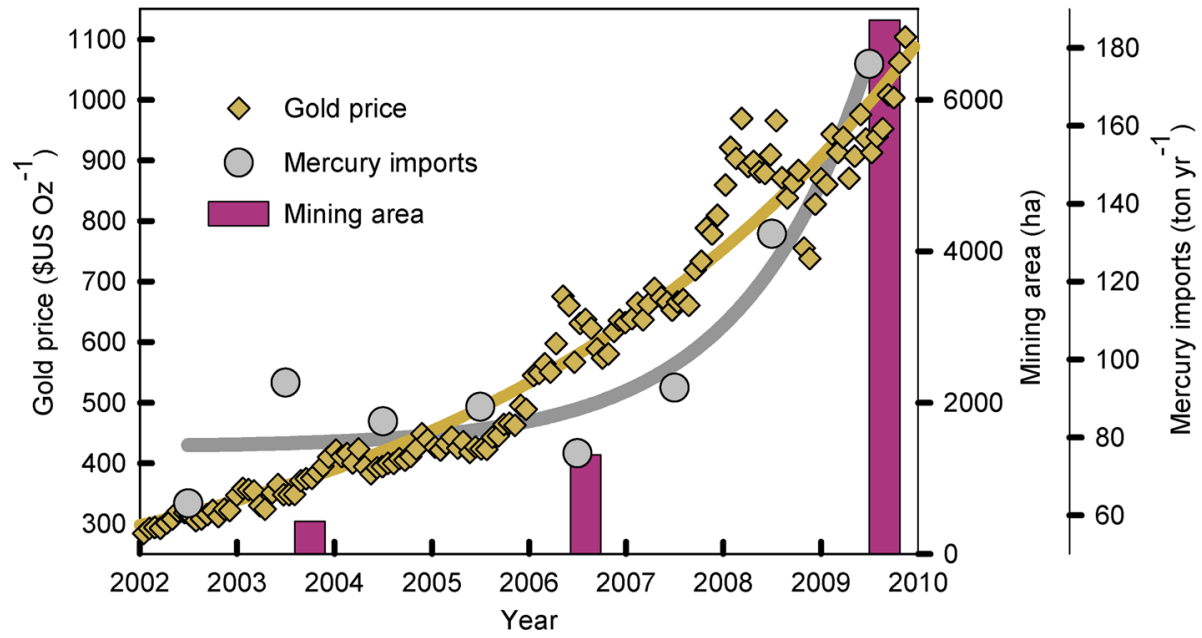

Fig. 4 Relationship between international gold prices, $\mathrm{Hg}$ imports, and extent of ASGM mining are in Peru. Reprinted from Swenson et al. (2011) 
estimating $\mathrm{Hg}$ exposure in human populations. However, discrepancies exist in the relationships between actual exposure as measured through dietary intake or inhalation estimates and realized exposure as measured through biomarkers (Christensen et al. 2016; Awata et al. 2017; Branco et al. 2017), suggesting that there are other drivers that modify the pathway from actual to realized $\mathrm{Hg}$ exposure. Over the past decade research has shown that genetic and epigenetic factors may influence realized $\mathrm{Hg}$ exposure (reviewed by Basu et al. 2014; Llop et al. 2015). For example, using data from a group of 469 dental professionals, Basu et al. (2014) estimated Hg intake through self-reported seafood consumption surveys, measured hair $\mathrm{Hg}$ levels, and genotyped all participants to try and better understand whether genetic information could improve exposure assessments. As expected, estimated $\mathrm{Hg}$ intake and hair $\mathrm{Hg}$ levels were positively correlated, but there was an interaction between $\mathrm{Hg}$ intake and genotype such that the intake-biomarker relationships differed among genotypes. Specifically, among avid fish consumers (i.e., those who ate six cans of tuna per week), there was an 8-fold difference in average hair Hg levels $(0.7-6.2 \mu \mathrm{g} / \mathrm{g})$ among those with different polymorphisms in the SEPP1 (rs7579) gene. Cross-sectional studies from across the world are also showing that polymorphisms in certain environmentally responsive genes (e.g., glutathione, metallothionein, and selenoenzyme families) are associated with the main effect (i.e., carriers of wildtype and variant genes have different $\mathrm{Hg}$ biomarker levels) and gene-environment interactions (i.e., exposure-biomarker relationships are different between carriers of the wildtype and variant genes). Similar observations linking genotype and realized $\mathrm{Hg}$ exposure have been made in studies of various populations, including dentists (Wang et al. 2011; Parajuli et al. 2016), students (Gundacker et al. 2007, 2009), Indiginous riverine populations (Barcelos et al. 2013, 2015), and gold miners (Custodio et al. 2005; Harari et al. 2012; Engstrom et al. 2013). Despite the expanding breadth of information on this topic, research to date has largely focused on adults and much less is known about the impact of genomic drivers on early-life $\mathrm{Hg}$ exposure situations or changes in $\mathrm{Hg}$ exposure across the life course. Further, most of the studies have focused on populations that are mainly exposed to elevated inorganic $\mathrm{Hg}$ sources, with $\mathrm{MeHg}$ exposures generally within background levels. Finally, there remain inconsistent findings across studies (see reviews by Basu et al. (2014) and Llop et al. 2015) which has limited the adoption of genetic factors into $\mathrm{Hg}$ risk assessment. If genetics plays a role in pharmacodynamic $\mathrm{Hg}$ routing and tissue distribution, then similar exposure profiles among individuals of different genotypes could result in large differences in biomarker concentrations. This not only influences the utility of biomarkers for estimating $\mathrm{Hg}$ risk, but may also be important for determining the sensitivity of individuals to $\mathrm{Hg}$ exposure. In addition to genetics, there is some emerging evidence from both animals (Pilsner et al. 2010; Basu et al. 2013) and humans (Hanna et al. 2012; Goodrich et al. 2013) to suggest that $\mathrm{Hg}$ is epigenetically active, and that $\mathrm{Hg}$-induced methylation of certain genes is associated with either a main effect of $\mathrm{Hg}$ exposure or a gene-environment interaction.

\section{Gastrointestinal factors}

Despite the common assumption that most (>95\%) ingested $\mathrm{MeHg}$ is bioavailable, substantial evidence exists suggesting that this may not be valid. In particular, a review by Bradley et al. (2017) identified a range of $\mathrm{MeHg}$ bioavailability in seafood, between 12 and 79\%, across 20 different studies. Factors such as type of seafood, cooking method, and the presence of certain nutrients all affected $\mathrm{Hg}$ bioavailability. More recently, because microbiota in the gut can affect the speciation of $\mathrm{Hg}$ prior to elimination, the impact of the gut microbiome has received attention for its role in the excretion of MeHg (Rothenberg et al. 2016). Thus, inaccuracies likely exist in estimates of exposure and risk that assume constant assimilation efficiencies of ingested MeHg.

\section{DOMAIN 3: INTERACTING EXTRINSIC AND INTRINSIC DRIVERS THAT INFLUENCE THE ADVERSE HEALTH EFFECTS OF MERCURY IN HUMANS AND WILDLIFE}

Mercury exposure can affect multiple organ systems, and manifests as diverse adverse health outcomes in humans, fish, and wildlife. The devastating neurologic impacts of acute, high-level $\mathrm{MeHg}$ and elemental $\mathrm{Hg}$ exposure are well documented, but chronic, low-level exposure also has important health impacts that are less well understood. A number of recent reviews have summarized the range of outcomes, known mechanisms, and toxicity benchmarks associated with different levels of $\mathrm{Hg}$ exposure or in situ $\mathrm{Hg}$ concentrations in humans (Karagas et al. 2012; Sheehan et al. 2014; Ha et al. 2017), fish (Depew et al. 2012a; Wiener et al. 2012), and wildlife (Scheuhammer and Sandheinrich 2008; Depew et al. 2012b). Together, this comprehensive collection of reviews highlights both the pervasive occurrence of deleterious health effects associated with environmentally relevant $\mathrm{Hg}$ exposures, as well as the tremendous variability in the range of exposures that induce those effects. The variability in $\mathrm{Hg}$ sensitivity suggests that the onset of $\mathrm{Hg}$ toxicity is likely mediated by various interacting extrinsic and intrinsic factors. In this section, we examine potential interactions between $\mathrm{Hg}$ and 
other drivers that affect the processes, mechanisms, and health outcomes of $\mathrm{Hg}$ toxicity. These drivers represent a range of scales and, where applicable, we relate the drivers that modulate the health effects of $\mathrm{Hg}$ with the extrinsic drivers of $\mathrm{Hg}$ bioaccumulation and exposure described in Domains 1 and 2. Because toxicity of $\mathrm{Hg}$ is ultimately a physiological process, we do not separate human health outcomes from those of wildlife or other animals, but instead integrate examples across taxa where relevant.

We examine the interactions of $\mathrm{Hg}$ exposure with various drivers that modulate organism health, such as the microbiome, infectious disease, coexposures to other toxicants, diet and nutrition, and genetics (Fig. 5). These interactions are not exclusive to one another, but for simplicity, we evaluate each one independently. The true interactions are likely much more complex as multiple drivers are acting simultaneously. These drivers may (1) chemically modify $\mathrm{Hg}$, as discussed in the "Microbiological factors: The microbiome and antibiotic resistance" section on microbiological factors; (2) modify associations between $\mathrm{Hg}$ exposure and disease, as covered in the "Immunotoxic effects of mercury and interactions with pathogens" section on infectious disease; (3) affect the risk of adverse health effects, as outlined in the "Nutrients and co-contaminants" section on diet and co-contaminants; or (4) independently increase the risks of $\mathrm{Hg}$-associated health outcomes, as discussed in the "Genetics" section on genetics.

\section{Microbiological factors: The microbiome and antibiotic resistance}

The microorganisms living commensally in and on humans and other animals exceed the number of somatic cells by a factor of 10 or more (Turnbaugh et al. 2007), and contain a number of genes that code for functions that support host physiology (Huttenhower et al. 2012). The aggregate genetic information encoded by these microbial communities is defined as the microbiome, and its recognition over the last decade has produced a paradigm shift regarding the role it plays in human and animal health (Kau et al. 2011; Muegge et al. 2011). The gut microbiome, in particular, is critical for immune function (Thaiss et al. 2016), nutrition (David et al. 2014), and xenobiotic metabolism (Dietert and Silbergeld 2015). Much is still unknown about the interactions between the microbiome and the health effects of $\mathrm{Hg}$ exposure, but emerging evidence suggests the presence of complex interactions that result in both positive and negative health outcomes for the host organism. For example, the gut microbiome can act as a co-factor that alters the toxicity of $\mathrm{Hg}$ by changing its speciation or sequestering $\mathrm{Hg}$ prior to absorption through biosorption and intracellular accumulation (Gadd 2010). The microbial genes responsible for $\mathrm{Hg}$ methylation have recently been found in both the vertebrate and invertebrate gut microbiome (Gilmour et al. 2013), and experimental studies have documented substantial $\mathrm{Hg}$ methylation within the digestive tracts of vertebrates (Rowland et al. 1975; Wang et al.
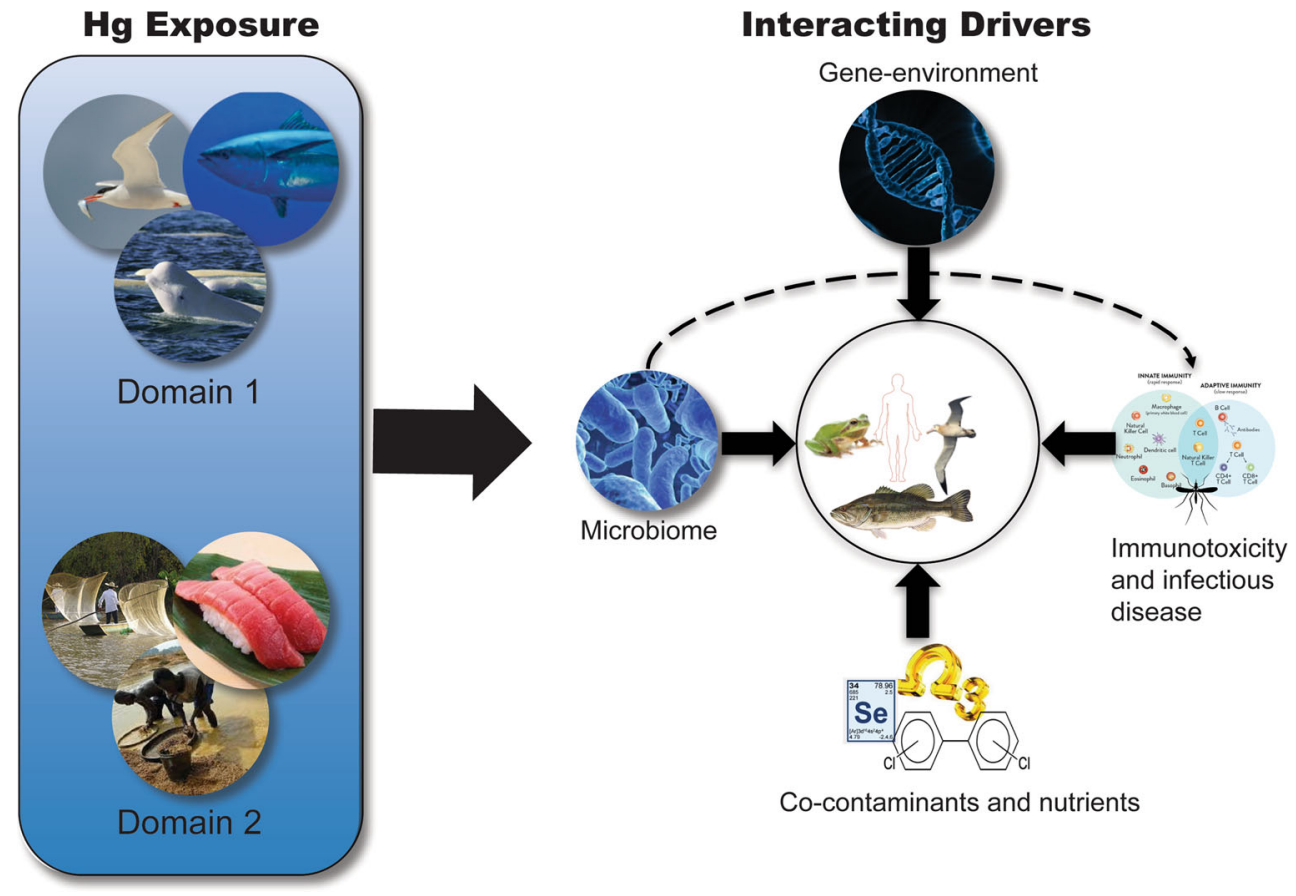

Fig. 5 Conceptual model for Domain 3, evaluating interactions between $\mathrm{Hg}$ exposure and key extrinsic and intrinsic drivers on adverse health outcomes in humans and wildlife 
2013; Martin-Doimeadios et al. 2017). Moreover, emerging empirical evidence suggests that the gut microbiome also may demethylate $\mathrm{Hg}$ (Rowland et al. 1984; Wang et al. 2017), potentially reducing its toxicity.

The relationship between $\mathrm{Hg}$, the gut microbiome, and host organisms extends beyond alterations of $\mathrm{Hg}$ toxicity in the host. Mercury sensitivity is common among microorganisms, and relatively low exposures may be lethal to many strains. Thus, Hg exposure can alter the gut microbiome itself, potentially affecting organism health (Madan et al. 2012). Mercury-induced changes to the microbiome can alter certain functional groups that are important for host physiology and health ( $\mathrm{Li}$ et al. 2008). However, the scientific evidence regarding the extent and importance of these outcomes is only starting to be generated and significant research is still needed. Some of the risk of $\mathrm{Hg}$ toxicity to the microbiome is ameliorated by $\mathrm{Hg}$-resistance genes that have evolved in many bacterial strains (Pal et al. 2015), and these genes can be exchanged among bacteria through horizontal gene transfer. Importantly, Hg-resistance genes are commonly associated and co-located with genes that also confer antibiotic resistance (Skurnik et al. 2010). Thus, Hg exposure can co-select for microbial communities in the gut that are resistant to both $\mathrm{Hg}$ and multiple antimicrobials ( $\mathrm{Li}$ et al. 2017). The interaction between $\mathrm{Hg}$ and antimicrobial resistance may be a particularly significant impact of $\mathrm{Hg}$ on the health of biota.

Antibiotic resistance is among the most pressing public health threats (Levy and Marshall 2004), and progress managing it remains a significant challenge. The potential contribution of $\mathrm{Hg}$ exposure to this expanding crisis could have important implications for the role of $\mathrm{Hg}$ in global health. However, only limited evidence exists regarding the magnitude of $\mathrm{Hg}$ 's contribution to global antibiotic resistance. The correlation between $\mathrm{Hg}$ exposure and antibiotic resistance emerged in the 1990s with the observation that use of dental amalgams led to shifts in fecal bacterial communities, with a higher proportion of $\mathrm{Hg}$-resistance genes present after amalgam use (Summers et al. 1993; Wireman et al. 1997). Resistance to antibiotics was substantially more prevalent in $\mathrm{Hg}$-resistant strains of bacteria than those that were Hg-sensitive (Summers et al. 1993; Wireman et al. 1997). More recently, it was shown that the Wayampi Amerindians from French Guyana, who have high level of $\mathrm{Hg}$ exposure but limited access to antibiotics and little contact with the outside world, had a higher prevalence of antibiotic-resistant $E$. coli in fecal samples than Europeans with low $\mathrm{Hg}$ exposure and ready access to modern antibiotics (Skurnik et al. 2010). Another study of 2522 fully sequenced bacterial genomes and 4582 plasmids from a range of environments found substantial co-occurrence patterns between $\mathrm{Hg}$-resistance and antibiotic-resistance genes (Pal et al. 2015). Moreover, antibiotic resistance was 2.5-10 times more prevalent in strains with varying expressions of $\mathrm{Hg}$-resistance genes than those without Hg-resistance genes (Pal et al. 2015). That study also found that humans and domestic animals were among the host environments with the most prevalent co-occurrence of strains for both $\mathrm{Hg}$ resistance and antibiotic resistance. In addition, many of the strains that exhibited co-occurrence were of pathogenic clinical significance, such as Escherichia, Staphylococcus, Salmonella, and Klebsiella. Still, little is known about the prevalence of $\mathrm{Hg}$ and antibiotic-resistance co-selection across different types of host taxa and its ubiquity in the environment. Recent work does suggest that co-selection extends to fish, where $\mathrm{Hg}$ exposure selected for gut microbiomes with up to 8-fold higher abundance of Hg-resistance genes, and resistance to multiple antibiotics was more common in $\mathrm{Hg}$ resistant, as opposed to $\mathrm{Hg}$-sensitive, bacterial colonies (Meredith et al. 2012; Lloyd et al. 2016).

Much more research is needed on the significance of this co-selection, but given the threat posed by antibacterial resistance to the health of humans and the environment, as well food security, it may have substantial, and as yet unquantified, implications regarding the health impacts of $\mathrm{Hg}$ exposure. Finally, the antibiotic resistance connection to $\mathrm{Hg}$ exposure may include important feedback loops leading to adverse effects of $\mathrm{Hg}$ toxicity, as both inorganic $\mathrm{Hg}$ and $\mathrm{MeHg}$ exposures can suppress immune function, increasing the likelihood of pathogenic infection (see "Immunotoxic effects of mercury and interactions with pathogens" section).

\section{Immunotoxic effects of mercury and interactions with pathogens}

One of the major health threats associated with global change drivers such as invasive species and shifting climates is the potential emergence, resurgence, and redistribution of infectious disease (Wu et al. 2016). Because $\mathrm{Hg}$ also affects immune function (Sweet and Zelikoff 2001; Crowe et al. 2017), changes in infectious disease patterns may have a significant effect on human health outcomes. The immunotoxic effects of low level exposures to various $\mathrm{Hg}$ species are not well known, but within the last decade, a growing body of evidence in animal models (Nyland et al. 2012), wild animals (Fallacara et al. 2011; Lewis et al. 2013; Desforges et al. 2016; Becker et al. 2017), and humans (Sweet and Zelikoff 2001; Silbergeld et al. 2010) points to a range of immune system interactions with elemental, inorganic and $\mathrm{MeHg}$ exposures. Different $\mathrm{Hg}$ species induce different types of immunotoxic responses (Gardner et al. 2010a), and the mechanisms of immunotoxicity depend upon the magnitude of $\mathrm{Hg}$ exposure. Higher $\mathrm{Hg}$ exposures can affect the abundance of cells 
responsible for mounting an immune response (dendritic, $\mathrm{B}$, and $\mathrm{T}$ cells), thereby impacting the majority of the production of cytokine signals. Conversely, lower-level $\mathrm{Hg}$ exposures only affect the production of cytokine signals, without changing immune cell counts (Silva et al. 2005b). This means that at lower $\mathrm{Hg}$ exposures, immune response can recover if cytokine-producing cells can return to basal function, whereas the death of immune cells at higher $\mathrm{Hg}$ exposures substantially inhibits immune response recovery. As in the nervous system, the immune system in many species, including humans, undergoes extensive pre- and postnatal development. Early exposures to $\mathrm{Hg}$ that are limited to in utero and early postnatal stages appear to reprogram the immune system, causing changes that persist into adulthood, long after exposure ceases (Silva et al. 2005a). Thus, Hg exposure can have long-lasting impacts on the ability of the immune system to respond stimulating events appropriately. The basic immune response is modified by these early exposures differently in males and females, and those changes affect the response to stimuli even into adulthood. Thus, males and females exposed to $\mathrm{Hg}$ early in life may have different risks in adulthood for autoimmunity and different responses to infection (Silva et al. 2005a).

The complexities of the interactions between immune function, disease, and $\mathrm{Hg}$ exposure are exemplified in experimental studies of the interactions between $\mathrm{Hg}$ and Coxsackievirus B3 infections. Early evidence indicated that viral infections altered the concentrations of $\mathrm{Hg}$ in target organs (Ilback et al. 2008), and the interaction between $\mathrm{Hg}$ exposure and disease response was dependent upon the relative timing of pathogen and $\mathrm{Hg}$ exposure. The virus alone could cause autoimmune myocarditis, whereas $\mathrm{Hg}$ alone had no myocarditic effect. However, when $\mathrm{Hg}$ exposure occurred prior to viral infection, the severity of autoimmune myocarditis was substantially increased, despite no changes in viral infectivity (Nyland et al. 2012). Conversely, $\mathrm{Hg}$ exposure after viral infection did not alter the severity of myocarditis compared to individuals who were not exposed to Hg (Nyland et al. 2012).

Despite experimental, correlational, and epidemiological evidence of $\mathrm{Hg}$ immunotoxicity, inconsistencies among studies, particularly those in human populations, have prevented rigorous risk assessments of the effects of $\mathrm{Hg}$ on immunological health. Some of these inconsistencies may be related to failure to account for interacting cofactors that modulate the $\mathrm{Hg}$-immunotoxicology link. For example, in a sample population of 692 children from the U.S., there was limited evidence of a relationship between blood $\mathrm{Hg}$ concentrations and either measles or rubella antibodies, but after stratifying based upon key nutritional status indicators, the population with specific nutritional deficiencies (high methylmalonic acid (MMA), low folate, high homocysteine) exhibited a positive relationship between blood $\mathrm{Hg}$ concentrations and antibody titers for the two viruses (Gallagher et al. 2011, 2013). Other inconsistencies exist between indices of autoimmunity and $\mathrm{Hg}$ exposure. Specifically, increased risks for autoimmune dysfunction, as determined by elevated serum titers of autoantibodies such as anti-nuclear autoantibodies (ANA), have been demonstrated for certain Hg-exposed populations in South America compared to unexposed groups (Silva et al. 2004; Gardner et al. 2010b; Nyland et al. 2011). However, no evidence for such an association was found in $\mathrm{Hg}$-exposed European and U.S. populations (Crowe et al. 2015; Monastero et al. 2017). Some work suggests that an interaction between $\mathrm{Hg}$ and malaria exposure may trigger Hg-induced autoimmunity in some populations but not others (see Box 3).

\section{Nutrients and co-contaminants}

Nutrients and other contaminants can have substantial ameliorative or exacerbating influences on $\mathrm{Hg}$ toxicity, complicating estimates of the health risks associated with Hg exposure (Rice 2008). Although there are potentially limitless combinations of coexposure mixtures that may influence health outcomes associated with $\mathrm{Hg}$ exposure, the most common include selenium (Se; (Cuvin-Aralar and Furness 1991; Hu et al. 2017), other biomagnifying contaminants such as polychlorinated biphenyls (PCBs) and other halogenated organic compounds (Braune et al. 2005; Burgess et al. 2005), co-occurring contaminants in pointsource situations such as lead and arsenic in mining areas (Basu et al. 2011, 2015a), and dietary nutrients like omega3 fatty acids (Gribble et al. 2016). Of these, Se is arguably the most compelling because of the extreme complexity and magnitude of its antagonistic interaction with $\mathrm{Hg}$, which has evoked the greatest discussion and debate with no clear consensus. The antagonistic relationship between $\mathrm{Hg}$ and $\mathrm{Se}$ has generated a broad body of literature including numerous review articles (Cuvin-Aralar and Furness 1991; Luque-Garcia et al. 2013; Bjorklund et al. 2017). Both in vitro and in situ studies from field and laboratory settings have demonstrated reduced severity of inorganic $\mathrm{Hg}$ and $\mathrm{MeHg}$ toxicity in response to Se exposure, but the degree of amelioration is at least partially dependent upon the Se species used and its exposure route. Selenite and organic Se compounds (selenocysteine and selenomethionine) tend to be more protective than species such as selenate (Cuvin-Aralar and Furness 1991; Khan and Wang 2009; Dang and Wang 2011). Although a consensus is still lacking, the ameliorative effects of $\mathrm{Se}$ on $\mathrm{Hg}$ toxicity have been postulated to occur through a range of mechanisms, including reducing assimilation and 


\section{Box 3 Mercury and malaria}

The relationship between $\mathrm{Hg}$ and malaria represents a complex interaction between $\mathrm{Hg}$ and the immune system. Malaria acts as a global driver that may influence $\mathrm{Hg}$ toxicity, and $\mathrm{Hg}$ can influence the immune response to malaria infection. The human response to malaria infection involves several layers of immediate and chronic events in the life cycle of the parasite, as well as interactions between activation and suppression of immune response, all of which may be affected by $\mathrm{Hg}$. Specifically, $\mathrm{Hg}$ exposure interacts with the human immune system to impair host resistance to the parasite (Silbergeld et al. 2000), increasing the likelihood of infection. Mercury also compromises the development of acquired immunity to malaria and may result in increased severity of the symptoms of infection (Silbergeld et al. 2000). In addition, $\mathrm{Hg}$ exposure that occurs subsequent to malaria infection induces autoimmune dysfunction. Epidemiological studies in areas with endemic malaria, coupled with exposures to $\mathrm{Hg}$ through ASGM and contaminated fish consumption found increased malaria infection rates compared to other populations (Dorea et al. 2003, 2005). In addition, biomarkers of autoimmune dysfunction were found to be common in Hg-exposed populations with a history of malaria contraction, whereas biomarkers were not detected in $\mathrm{Hg}$-exposed populations with limited malaria exposure (Motts et al. 2014).

Malaria-endemic areas of the world exhibit a substantial geographic overlap with major regions of ASGM. This creates a nexus for potential interactions between $\mathrm{Hg}$ and malaria exposure that can exacerbate the deleterious effects associated with these individual stressors. Evidence of these interactions exist from studies in Brazil (Duarte and Fontes 2002). Increases in gold prices stimulated expansion of ASGM activities throughout Amazonia, and physical activities associated with mining, coupled with an increase in human occupancy, resulted in a rapid increase in the incidence of malaria infections. Specifically, the alteration of stream habitats created new breeding habitats for Anopheles mosquito vectors of malaria (de Oliveira et al. 2013). In addition, much of the population attracted to gold mining in remote areas for work and economic gain were immunologically naïve in terms of exposure to malaria and thus potentially more likely to contract malaria (Doolan et al. 2009). As the workers moved back and forth between the mining areas and their places of origin, they transported malaria with them, increasing rates of infection outside Amazonia (Silbergeld et al. 2002). Thus, global socioeconomic drivers (gold prices) influenced human exposure to $\mathrm{Hg}$ in this region, which may have indirectly contributed to the spread of malaria to more populated regions. In addition, given the documented interactions between $\mathrm{Hg}$ and malaria exposure, it is likely that human health was additionally compromised.

Cumulatively, this series of findings has significant public health implications and suggests that interactions between $\mathrm{Hg}$ and infectious diseases may be an understudied but highly relevant aspect of the risks to human and ecological health posed by $\mathrm{Hg}$ exposure. In addition, the distribution of many pathogens is currently being altered by climate change, which is facilitating the spread of their intermediate hosts (Wu et al. 2016). Indeed, models predict that under a range of forecasted climate scenarios, the distribution of malaria is likely to expand, particularly into higher elevations of tropical latitudes (Caminade et al. 2014). Further quantification of the health implications of the malaria$\mathrm{Hg}$ interaction will facilitate estimates of future risks. facilitating elimination of $\mathrm{MeHg}$ (Bjerregaard et al. 2011; Bjerregaard and Christensen 2012; Li et al. 2012; Huang et al. 2013), rendering $\mathrm{Hg}$ biologically unavailable through covalent bonding between $\mathrm{Hg}$ and Se (Yang et al. 2008), demethylation of $\mathrm{MeHg}$ in the liver or other organs (Eagles-Smith et al. 2009; Khan and Wang 2009), or through supporting the glutathione antioxidant pathway (Sormo et al. 2011). Various degrees of empirical support exist for each of these mechanisms, highlighting both the complexity of the $\mathrm{Hg}$-Se interaction as well as its ubiquity across physiological processes. One commonly referenced concept emerging from the body of work on $\mathrm{Hg}-\mathrm{Se}$ interactions is the contention that $\mathrm{Se} \mathrm{Hg}$ molar ratios greater than 1 confer protection from manifestations of $\mathrm{Hg}$ toxicity, whereas molar ratios less than 1 indicate a lack of protection from Se. This hypothesis served as a foundational concept for a more recently posited mechanism for $\mathrm{Hg}$ toxicity - that $\mathrm{Hg}$ irreversibly binds with $\mathrm{Se}$, thereby interrupting the synthesis of critical selenoenzymes, creating a Se deficiency syndrome that disrupts many aspects of an organism's physiology (Ralston and Raymond 2010). According to this proposed mechanism, the amount of Se would need to exceed a Se:Hg molar ratio of 1 in either diet or tissues, so that it could confer a protective effect against $\mathrm{MeHg}$ toxicity. Although intriguing, some studies challenge the validity of this hypothesis, as discussed below.

Contemporary research continues to demonstrate a lack of clarity regarding whether Se provides universal protection for $\mathrm{MeHg}$ exposure, or is specific to only some mechanisms of action, such as neurotoxicity. For example, dietary selenocysteine did not reduce $\mathrm{MeHg}$ uptake, or enhance $\mathrm{Hg}$ elimination in captive mink (Evans et al. 2016). In addition, $\mathrm{MeHg}$ toxicity in harbor seal lymphocytes was not ameliorated by $\mathrm{Se}$, even at $\mathrm{Se}: \mathrm{Hg}$ molar ratios of up to 101 (Das et al. 2016), whereas similar studies in beluga whales indicated only limited protection from Se at the highest MeHg doses (Frouin et al. 2012). Perhaps most important in terms of deviations from the idea of $\mathrm{Hg}-\mathrm{Se}$ antagonism is their interaction with respect to reproduction. Recent studies have documented deleterious synergistic relationships between $\mathrm{Hg}$ and $\mathrm{Se}$ to both bird (Heinz et al. 2012) and fish (Penglase et al. 2014) reproduction. Specifically, at elevated Se exposures, $\mathrm{Hg}$ appears to exacerbate Se-induced reproductive toxicity. Few studies have experimentally tested this relative to other $\mathrm{Hg}-\mathrm{Se}$ outcomes, and it is unclear if these interactions are constrained to only egg-laying species, or if viviparous placental reproduction is subject to a similar synergism. Regardless, these experimental findings highlight the need to continue developing a quantitative understanding of the mechanistic role of Se across $\mathrm{Hg}$ toxicity endpoints, and suggest that application of the $\mathrm{Se}: \mathrm{Hg}$ molar ratio hypothesis may not be a panacea for 
reducing $\mathrm{Hg}$-associated health risks in humans and wildlife.

Other dietary nutrients may also offset the deleterious effects of MeHg exposure, although not as directly as occurs with Se. Interactions with omega-3 fatty acids, such as eicopentaenoic acid (EPA) and docosahexaenoic acid (DHA), are of particular interest because of their known health benefits and co-occurrence at high concentrations with $\mathrm{Hg}$ in many marine fish species (Mozaffarian and Rimm 2006; Gribble et al. 2016). The potential interactions with $\mathrm{Hg}$ have largely focused on neurodevelopmental and cardiovascular outcomes. In general, limited evidence exists for substantial antagonism of $\mathrm{Hg}$ by omega-3 fatty acids, although some studies have found that accounting for omega-3 fatty acid or fish intake can improve estimates of $\mathrm{Hg}$ impairment for certain populations, suggesting that these fatty acids might have an ameliorating effect (Oken et al. 2008; Choi et al. 2014). Others have found that when populations are stratified by their levels of omega-3 fatty acids, relationships between $\mathrm{Hg}$ exposure and adverse outcome biomarkers such as oxidative stress tend to be enhanced in those with low omega-3 levels, and weakened in those with high omega-3 levels (Karimi et al. 2016b). The specific mechanisms underlying any potential protective effects of nutrients on $\mathrm{MeHg}$ toxicity have not been fully elucidated (Ha et al. 2017). Since $\mathrm{MeHg}$ and these nutrients are often present in the same exposure sources and affect the same toxicity endpoints, quantifying their individual effects and interactions is challenging. Despite this, the benefits of fish consumption on health parameters is well known, and developing quantitative tools to better determine the riskbenefit coefficient is needed to facilitate recommendations for balancing potential health concerns about $\mathrm{MeHg}$ exposure against the benefits afforded by key nutrients found in seafood (Chapman and Chan 2000).

Whereas nutrients such as Se and omega-3 fatty acids can help offset the negative consequences of $\mathrm{Hg}$ exposure, coexposure to other contaminants can have the opposite effect. Of particular concern are other biomagnifying contaminants, such as PCBs and other organohalogenated compounds, that may co-accumulate with $\mathrm{MeHg}$ and affect the same physiological systems impaired by $\mathrm{Hg}$. Similar to omega-3 fatty acids, many other bioaccumulative contaminants in the environment exhibit collinearity with $\mathrm{MeHg}$ exposure, which can confound the determination of the interactive effects on organism health. In vitro and in vivo laboratory studies testing responses to $\mathrm{Hg}$ and co-contaminant exposures alone and in combination suggest that $\mathrm{PCBs}$ in particular interact with $\mathrm{MeHg}$ exposure to elicit neurologic effects when isolated exposures do not (Bemis and Seegal 1999; Roegge et al. 2004; Fischer et al. 2008; Cauli et al. 2013). Similarly, epidemiological studies with individuals stratified by $\mathrm{Hg}$ or $\mathrm{PCB}$ exposure indicate potential interactive effects, such as PCB-associated neurologic deficits only in the highest tertile of $\mathrm{Hg}$ exposure (Grandjean et al. 2001), or negative associations between prenatal $\mathrm{MeHg}$ exposure and cognitive abilities only in those with elevated prenatal PCB exposure (Stewart et al. 2003). Although limited, recent field studies with wildlife suggest that $\mathrm{MeHg}$ exposure may also interact with other endocrine-disrupting compounds to influence hormone expression, disturbance response, and reproduction (Goutte et al. 2015; Tartu et al. 2015a, b). Similarly, there is emerging evidence that many ASGM sites are cocontaminated with lead, arsenic, and cadmium (Basu et al. 2015b; Tirima et al. 2016), and more work is needed to better understand the toxicologic implications of these coexposures. Given the abundance of studies measuring coexposure of other contaminants with $\mathrm{Hg}$, it is surprising that so few have quantitatively tested for interactive effects. This is clearly a major data gap, and more accurate determinations of risk from $\mathrm{Hg}$ coexposure with nutrients and other contaminants, in both epidemiological and field-based studies on humans and wildlife, are needed.

\section{Genetics}

Although external environmental factors can influence individual sensitivity to $\mathrm{Hg}$ exposure, genetic and epigenetic factors may influence $\mathrm{Hg}$ exposure-outcome associations through alterations in toxicokinetics and toxicodynamics. In "Genetics" section, we outlined how carriers of certain genetic polymorphisms can have altered $\mathrm{Hg}$ exposure biomarkers. Other researchers have shown that neurodevelopmental disorders (Mitchell 2011) and cardiovascular disease (Ehret et al. 2011), both of which are relevant in terms of $\mathrm{Hg}$-associated health risks, have genetic underpinnings and more importantly, are driven by complex gene-environment interactions. There is a limited, though slowly growing, body of evidence demonstrating that $\mathrm{Hg}$ gene-environment interactions are an important feature to be considered. For example, several studies have reported that $\mathrm{Hg}$-associated effects on atypical urinary porphyrin excretion, neurobehavioral tests, and visual-motor performance were modified by genetic polymorphisms (reviewed by Basu et al. (2014)). Another study reported that the offspring of mothers with GSTM1 and GSTT1 deletions (genes involved in glutathione function) and higher blood $\mathrm{Hg}$ levels had increased risk for low birth weight (Lee et al. 2010). Variation in responses to $\mathrm{MeHg}$ exposure among families suggests that susceptibility to $\mathrm{Hg}$ exposure may be heritable (Varian-Ramos et al. 2013). Importantly, recent work with zebrafish demonstrated transgenerational abnormalities in the neurobehavior of unexposed F2 generation fish, and that the proximate cause was sperm epimutations in Hg-exposed parents (Carvan et al. 2017). These findings suggest $\mathrm{Hg}$ exposure in wild populations could have multigenerational effects on fitness, even after exposure is reduced. The prevalence of heritable neurodeficits due to $\mathrm{Hg}$ exposure in previous generations is unknown, but 
these findings indicated that germ-line genes appear to be targets for $\mathrm{MeHg}$ genotoxicity.

\section{SUMMARY AND RESEARCH NEEDS}

Persistent knowledge gaps that can exist between $\mathrm{Hg}$ releases, bioaccumulation, and exposure, and the risks of deleterious health impacts to humans and other animals can create substantial uncertainty regarding the efficacy of $\mathrm{Hg}$ reduction and mitigation actions. Intrinsic biological factors and extrinsic ecological and socioeconomic factors are important modulators of the realized exposures to $\mathrm{MeHg}$ and inorganic $\mathrm{Hg}$, as well as health impacts on $\mathrm{Hg}$-exposed organisms. Therefore, as Hg-reduction and mitigation efforts proceed, a quantitative understanding is needed of how these extrinsic and intrinsic drivers interact on the global, individual, and molecular scales to influence the risk of $\mathrm{Hg}$ exposure, toxicity, and associated health effects. Incorporating additional metrics representing these factors into monitoring programs would facilitate tractable approaches to statistically account for their interactive effects on Hg-related risks. Specifically, understanding the global extrinsic drivers that affect the four mechanisms of $\mathrm{MeHg}$ bioaccumulation and biomagnification (primary productivity, habitat use, bioenergetics, and food web structure) will help partition out their influence on $\mathrm{Hg}$ concentrations in ecosystems. To do so requires refining the quantitative understanding of how each of the four underlying mechanisms $\mathrm{MeHg}$ bioaccumulation act, and in what contexts they are altered by global extrinsic drivers. Development of data application tools that facilitate incorporating these metrics into monitoring programs with a standardized approach is an important need, and would enable more robust comparisons of analogous temporal trends of $\mathrm{Hg}$ bioaccumulation among geographically diverse locations.

The emergence of high-throughput genetic tools has opened new avenues for understanding (1) how intrinsic genetic factors influence assimilation of and sensitivity to $\mathrm{Hg}$; (2) epigenetic responses to $\mathrm{Hg}$ exposure that can reveal specific mechanisms of action; and (3) interactions between the gut microbiome and $\mathrm{Hg}$. These emerging areas represent potentially important contributions to the field for refining risk estimates based on genetic variation among populations, and for developing more effective biomarkers of $\mathrm{Hg}$ exposure. Substantial research in these areas is still needed for them to be applicable to public health and ecological conservation. Similarly, not enough is known about the interactions between $\mathrm{Hg}$ exposure, immunotoxicity, and infectious disease. Clearly the immune system is highly sensitive to both inorganic $\mathrm{Hg}$ and $\mathrm{MeHg}$ exposure, but extrapolating that sensitivity to the toxicologic implications at the whole organism scale is an important next step, particularly as it relates to infectious disease interactions. Finally, despite nearly five decades of research, and evidence from hundreds of scientific articles supporting Se as strong antagonist to $\mathrm{Hg}$ toxicity, there is still no consensus regarding the efficacy of Se in ameliorating different manifestations of $\mathrm{Hg}$ toxicity. Consequently, widely accepted tools for incorporating Se into health risk assessment for $\mathrm{Hg}$ exposure are still lacking. New criteria are emerging that take into account some of the mechanisms of the $\mathrm{Hg}-\mathrm{Se}$ antagonism (Zhang et al. 2014; Ralston et al. 2016); however, extensive epidemiologic research is still needed to validate their safety for health risk assessments and their applicability to wildlife health. This is an important research direction that deserves continued focus. This paper demonstrates that the context within which $\mathrm{Hg}$ exposure occurs in the environment is a critical aspect that influences risk of exposure and adverse health outcomes. Future efforts to develop context-dependent assessments will facilitate improved risk estimates for humans and wildlife.

Acknowledgements The paper was written as part of the synthesis effort for the 13th International Conference on Mercury as a Global Pollutant, Providence, Rhode Island, July 16-21, 2017. It was supported by Dartmouth College Toxic Metals Superfund Research Program through funds from the National Institute of Environmental Health under Award Number R13 ES028077-01 and Award Number P42ES007373. Funding was also provided by the USGS Environmental Health Mission Area, Contaminant Biology Program. The IUF (Institut Universitaire de France) is thanked for its support to PB. We appreciate the technical comments and supports of Celia Chen and Charley Driscoll, and the insightful comments and editing of Stacey Tobin and two anonymous reviewers. Any use of trade, product, or firm names is for descriptive purposes only and does not imply endorsement by the U.S. Government.

Open Access This article is distributed under the terms of the Creative Commons Attribution 4.0 International License (http:// creativecommons.org/licenses/by/4.0/), which permits unrestricted use, distribution, and reproduction in any medium, provided you give appropriate credit to the original author(s) and the source, provide a link to the Creative Commons license, and indicate if changes were made.

\section{REFERENCES}

Ackerman, J.T., C.A. Eagles-Smith, and M.P. Herzog. 2011. Bird mercury concentrations change rapidly as chicks age Toxicological risk is highest at hatching and fledging. Environmental Science and Technology 45: 5418-5425.

Ackerman, J.T., C.A. Hartman, C.A. Eagles-Smith, M.P. Herzog, J. Davis, G. Ichikawa, and A. Bonnema. 2015. Estimating mercury exposure of piscivorous birds and sport fish using prey fish monitoring. Environmental Science and Technology 49: 13596-13604.

Ackerman, J.T., C.A. Eagles-Smith, M.P. Herzog, C.A. Hartman, S.H. Peterson, D.C. Evers, and C.E. Bryan. 2016. Avian mercury exposure and toxicological risk across western North America: A synthesis. Science of the Total Environment 568: 749-769. 
AMAP. 2015. AMAP Assessment 2015: Human health in the arctic. Oslo: Arctic Monitoring and Assessment Programme (AMAP).

Atcheson, M.E., K.W. Myers, D.A. Beauchamp, and N.J. Mantua. 2012. Bioenergetic response by steelhead to variation in diet, thermal habitat, and climate in the North Pacific Ocean. Transactions of the American Fisheries Society 141: 1081-1096.

Awata, H., S. Linder, L.E. Mitchell, and G.L. Delclos. 2017. Association of dietary intake and biomarker levels of arsenic, cadmium, lead, and mercury among Asian populations in the United States: NHANES 2011-2012. Environmental Health Perspectives 125: 314-323.

Barcelos, G.R.M., D. Grotto, K.C. de Marco, J. Valentini, A.V. Lengert, A.A.S. de Oliveira, and F. Barbosa. 2013. Polymorphisms in glutathione-related genes modify mercury concentrations and antioxidant status in subjects environmentally exposed to methylmercury. Science of the Total Environment 463: 319-325.

Barcelos, G.R.M., M.F. de Souza, A.A.S. de Oliveira, A.V. Lengert, M.T. de Oliveira, R. Camargo, and F. Barbosa. 2015. Effects of genetic polymorphisms on antioxidant status and concentrations of the metals in the blood of riverside Amazonian communities co-exposed to $\mathrm{Hg}$ and $\mathrm{Pb}$. Environmental Research 138: 224-232.

Basu, N., C.J. Stamler, K.M. Loua, and H.M. Chan. 2005. An interspecies comparison of mercury inhibition on muscarinic acetylcholine receptor binding in the cerebral cortex and cerebellum. Toxicology and Applied Pharmacology 205: 71-76.

Basu, N., D.H. Nam, E. Kwansaa-Ansah, E.P. Renne, and J.O. Nriagu. 2011. Multiple metals exposure in a small-scale artisanal gold mining community. Environmental Research 111: 463-467.

Basu, N., J. Head, D.H. Nam, J.R. Pilsner, M.J. Carvan, H.M. Chan, and A.M. Scheuhammer. 2013. Effects of methylmercury on epigenetic markers in three model species: Mink, chicken and yellow perch. Comparative Biochemistry and Physiology C-Toxicology \& Pharmacology 157: 322-327.

Basu, N., J.M. Goodrich, and J. Head. 2014. Ecogenetics of mercury: From genetic polymorphisms and epigenetics to risk assessment and decision-making. Environmental Toxicology and Chemistry 33: $1248-1258$.

Basu, N., E. Clarke, A. Green, B. Calys-Tagoe, L. Chan, M. Dzodzomenyo, and M.L. Wilson. 2015a. Integrated assessment of artisanal and small-scale gold mining in ghana-part 1: Human health review. International Journal of Environmental Research and Public Health 12: 5143-5176.

Basu, N., E.P. Renne, and R.N. Long. 2015b. An integrated assessment approach to address artisanal and small-scale gold mining in Ghana. International Journal of Environmental Research and Public Health 12: 11683-11698.

Baum, J.K., and B. Worm. 2009. Cascading top-down effects of changing oceanic predator abundances. Journal of Animal Ecology 78: 699-714.

Baumann, Z., R.P. Mason, D.O. Conover, P. Balcom, C.Y. Chen, K.L. Buckman, and H. Baumann. 2017. Mercury bioaccumulation increases with latitude in a coastal marine fish (Atlantic silverside, Menidia menidia). Canadian Journal of Fisheries and Aquatic Sciences 74: 1009-1015.

Baxter, C.V., K.D. Fausch, M. Murakami, and P.L. Chapman. 2004. Fish invasion restructures stream and forest food webs by interrupting reciprocal prey subsidies. Ecology 85: 2656-2663.

Becker, D.J., M.M. Chumchal, A.B. Bentz, S.G. Platt, G.Á. Czirják, T.R. Rainwater, S. Altizer, and D.G. Streicker. 2017. Predictors and immunological correlates of sublethal mercury exposure in vampire bats. Royal Society Open Science 4: 170073.

Bemis, J.C., and R.F. Seegal. 1999. Polychlorinated biphenyls and methylmercury act synergistically to reduce rat brain dopamine content in vitro. Environmental Health Perspectives 107: 879-885.
Bergeron, C.M., W.A. Hopkins, B.D. Todd, M.J. Hepner, and J.M. Unrine. 2011. Interactive effects of maternal and dietary mercury exposure have latent and lethal consequences for amphibian larvae. Environmental Science and Technology 45: 3781-3787.

Bjerregaard, P., and A. Christensen. 2012. Selenium reduces the retention of methyl mercury in the brown Shrimp Crangon crangon. Environmental Science and Technology 46: 6324-6329.

Bjerregaard, P., S. Fjordside, M.G. Hansen, and M.B. Petrova. 2011. Dietary selenium reduces retention of methyl mercury in freshwater fish. Environmental Science and Technology 45: 9793-9798.

Bjorklund, G., J. Aaseth, O.P. Ajsuvakova, A.A. Nikonorov, A.V. Skalny, M.G. Skalnaya, and A.A. Tinkov. 2017. Molecular interaction between mercury and selenium in neurotoxicity. Coordination Chemistry Reviews 332: 30-37.

Bodaly, R.A., W.A. Jansen, A.R. Majewski, R.J. Fudge, N.E. Strange, A.J. Derksen, and D.J. Green. 2007. Postimpoundment time course of increased mercury concentrations in fish in hydroelectric reservoirs of northern Manitoba, Canada. Archives of Environmental Contamination and Toxicology 53: 379-389.

Bradley, M.A., B.D. Barst, and N. Basu. 2017. A review of mercury bioavailability in humans and fish. International Journal of Environmental Research and Public Health 14: 169.

Branco, V., S. Caito, M. Farina, J.T. da Rocha, M. Aschner, and C. Carvalho. 2017. Biomarkers of mercury toxicity: Past, present, and future trends. Journal of Toxicology and Environmental Health-Part B-Critical Reviews 20: 119-154.

Braune, B.M., P.M. Outridge, A.T. Fisk, D.C. Muir, P.A. Helm, K. Hobbs, and I. Stirling. 2005. Persistent organic pollutants and mercury in marine biota of the Canadian Arctic: An overview of spatial and temporal trends. Science of the Total Environment 351-352: 4-56.

Bridges, K.N., B.K. Soulen, C.L. Overturf, P.E. Drevnick, and A.P. Roberts. 2016. Embryotoxicity of maternally transferred methylmercury to fathead minnows (Pimephales promelas). Environmental Toxicology and Chemistry 35: 1436-1441.

Brinkmann, L., and J.B. Rasmussen. 2010. High levels of mercury in biota of a new Prairie irrigation reservoir with a simplified food web in Southern Alberta, Canada. Hydrobiologia 641: 11-21.

Burgess, N.M., and M.W. Meyer. 2008. Methylmercury exposure associated with reduced productivity in common loons. Ecotoxicology 17: 83-91.

Burgess, N.M., D.C. Evers, and J.D. Kaplan. 2005. Mercury and other contaminants in common loons breeding in Atlantic Canada. Ecotoxicology 14: 241-252.

Caminade, C., S. Kovats, J. Rocklov, A.M. Tompkins, A.P. Morse, F.J. Colon-Gonzalez, and S.J. Lloyd. 2014. Impact of climate change on global malaria distribution. Proceedings of the National Academy of Sciences USA 111: 3286-3291.

Cantoral, A., C. Batis, and N. Basu. 2017. National estimation of seafood consumption in Mexico: Implications for exposure to methylmercury and polyunsaturated fatty acids. Chemosphere 174: 289-296.

Canuel, R., S.B. de Grosbois, M. Lucotte, P. Arp, C. Ritchie, D. Mergler, and R. Anderson. 2006. New evidence on variations of human body burden of methylmercury from fish consumption. Environmental Health Perspectives 114: 302-306.

Carpenter, S.R., and E.M. Bennett. 2011. Reconsideration of the planetary boundary for phosphorus. Environmental Research Letters 6: 014009.

Carpenter, S.R., N.F. Caraco, D.L. Correll, R.W. Howarth, A.N. Sharpley, and V.H. Smith. 1998. Nonpoint pollution of surface waters with phosphorus and nitrogen. Ecological Applications 8: 559-568.

Carvan, M.J., T.A. Kalluvila, R.H. Klingler, J.K. Larson, M. Pickens, F.X. Mora-Zamorano, V.P. Connaughton, I. Sadler-Riggleman, 
et al. 2017. Mercury-induced epigenetic transgenerational inheritance of abnormal neurobehavior is correlated with sperm epimutations in zebrafish. PLOS ONE 12: e0176155.

Cauli, O., B. Piedrafita, M. Llansola, and V. Felipo. 2013. Gender differential effects of developmental exposure to methyl-mercury, polychlorinated biphenyls 126 or 153 , or its combinations on motor activity and coordination. Toxicology 311: 61-68.

Chan, H.M., A.M. Scheuhammer, A. Ferran, C. Loupelle, J. Holloway, and S. Weech. 2003. Impacts of mercury on freshwater fish-eating wildlife and humans. Human and Ecological Risk Assessment 9: 867-883.

Chapman, L., and H.M. Chan. 2000. The influence of nutrition on methyl mercury intoxication. Environmental Health Perspectives 108: 29-56.

Chen, C., and C.L. Folt. 2005. High plankton densities reduce mercury biomagnification. Envionmental Science and Technology 39: 115-121.

Choi, A.L., U.B. Mogensen, K.S. Bjerve, F. Debes, P. Weihe, P. Grandjean, and E. Budtz-Jorgensen. 2014. Negative confounding by essential fatty acids in methylmercury neurotoxicity associations. Neurotoxicology and Teratology 42: 85-92.

Christensen, N.S., A.W. Wood, N. Voisin, D.P. Lettenmaier, and R.N. Palmer. 2004. The effects of climate change on the hydrology and water resources of the Colorado River basin. Climatic Change 62: 337-363.

Christensen, K.Y., B.A. Thompson, M. Werner, K. Malecki, P. Imm, and H.A. Anderson. 2016. Levels of persistent contaminants in relation to fish consumption among older male anglers in Wisconsin. International Journal of Hygiene and Environmental Health 219: 184-194.

Chumchal, M.M., and R.W. Drenner. 2015. An environmental problem hidden in plain sight? Small Human-made ponds, emergent insects, and mercury contamination of biota in the Great Plains. Environmental Toxicology and Chemistry 34: 1197-1205.

Cisneros-Montemayor, A.M., D. Pauly, L.V. Weatherdon, and Y. Ota. 2016. A global estimate of seafood consumption by coastal indigenous peoples. PLOS ONE 11: e0166681.

Clarkson, T.W., and L. Magos. 2006. The toxicology of mercury and its chemical compounds. Critical Reviews in Toxicology 36: 609-662.

Copan, L., J. Fowles, T. Barreau, and N. McGee. 2015. Mercury toxicity and contamination of households from the use of skin creams adulterated with mercurous chloride (Calomel). International Journal of Environmental Research and Public Health 12: 10943-10954.

Crowe, W., L. Breslin, G. Watson, A. Bell, J. Strain, P. Allsopp, and E. McSorley. 2015. Hair mercury is inversely related to disease associated damage in systemic lupus erythematosus. Clinical and Experimental Rheumatology 33: S81-S81.

Crowe, W., P.J. Allsopp, G.E. Watson, P.J. Magee, J.J. Strain, D.J. Armstrong, and E.M. McSorley. 2017. Mercury as an environmental stimulus in the development of autoimmunity-a systematic review. Autoimmunity Reviews 16: 72-80.

Custodio, H.M., R. Harari, L. Gerhardsson, S. Skerfving, and K. Broberg. 2005. Genetic influences on the retention of inorganic mercury. Archives of Environmental Health 60: 17-23.

Cuvin-Aralar, M.L.A., and R.W. Furness. 1991. Mercury and Selenium Interaction-a review. Ecotoxicology and Environmental Safety 21: 348-364.

Dale, V.H. 1997. The relationship between land-use change and climate change. Ecological Applications 7: 753-769.

Dang, F., and W.X. Wang. 2011. Antagonistic interaction of mercury and selenium in a marine fish is dependent on their chemical species. Environmental Science and Technology 45: 3116-3122.
Das, K., A. Dupont, M.C. De Pauw-Gillet, C. Debier, and U. Siebert. 2016. Absence of selenium protection against methylmercury toxicity in harbour seal leucocytes in vitro. Marine Pollution Bulletin 108: 70-76.

Daskalov, G.M., A.N. Grishin, S. Rodionov, and V. Mihneva. 2007. Trophic cascades triggered by overfishing reveal possible mechanisms of ecosystem regime shifts. Proceedings of the National Academy of Sciences USA 104: 10518-10523.

David, L.A., C.F. Maurice, R.N. Carmody, D.B. Gootenberg, J.E. Button, B.E. Wolfe, A.V. Ling, A.S. Devlin, et al. 2014. Diet rapidly and reproducibly alters the human gut microbiome. Nature 505: 559-563.

de Oliveira, E.C., E.S. dos Santos, P. Zeilhofer, R. Souza-Santos, and M. Atanaka-Santos. 2013. Geographic information systems and logistic regression for high-resolution malaria risk mapping in a rural settlement of the southern Brazilian Amazon. Malaria Journal 12: 420.

Depew, D.C., N. Basu, N.M. Burgess, L.M. Campbell, E.W. Devlin, P.E. Drevnick, and J.G. Wiener. 2012a. Toxicity of dietary methylmercury to fish: derivation of ecologically meaningful threshold concentrations. Environmental Toxicology and Chemistry 31: 1536-1547.

Depew, D.C., N. Basu, N.M. Burgess, L.M. Campbell, D.C. Evers, K.A. Grasman, and A.M. Scheuhammer. 2012b. Derivation of screening benchmarks for dietary methylmercury exposure for the common loon (Gavia immer): Rationale for use in ecological risk assessment. Environmental Toxicology and Chemistry 31: 2399-2407.

Desforges, J.P.W., C. Sonne, M. Levin, U. Siebert, S. De Guise, and R. Dietz. 2016. Immunotoxic effects of environmental pollutants in marine mammals. Environment International 86: 126-139.

Dietert, R.R., and E.K. Silbergeld. 2015. Biomarkers for the 21st century: Listening to the microbiome. Toxicological Sciences 144: 208-216.

Dijkstra, J.A., K.L. Buckman, D. Ward, D.W. Evans, M. Dionne, and C.Y. Chen. 2013. Experimental and natural warming elevates mercury concentrations in estuarine fish. PLOS ONE 8: e58401.

Dlova, N.C., S.H. Hamed, J. Tsoka-Gwegweni, and A. Grobler. 2015. Skin lightening practices: an epidemiological study of South African women of African and Indian ancestries. British Journal of Dermatology 173: 2-9.

Doolan, D.L., C. Dobano, and J.K. Baird. 2009. Acquired Immunity to Malaria. Clinical Microbiology Reviews 22: 13-36.

Dorcas, M.E., J.D. Willson, R.N. Reed, R.W. Snow, M.R. Rochford, M.A. Miller, and K.M. Hart. 2012. Severe mammal declines coincide with proliferation of invasive Burmese pythons in Everglades National Park. Proceedings of the National Academy of Sciences USA 109: 2418-2422.

Dorea, J.G. 2017. Low-dose thimerosal in pediatric vaccines: Adverse effects in perspective. Environmental Research 152: 280-293.

Dorea, J.G., A.C. Barbosa, I. Ferrari, and J.R. De Souza. 2003. Mercury in hair and in fish consumed by Riparian women of the Rio Negro, Amazon, Brazil. Journal of Environmental Health Research 13: 239-248.

Dorea, J.G., J.R. de Souza, P. Rodrigues, I. Ferrari, and A.C. Barbosa. 2005. Hair mercury (signature of fish consumption) and cardiovascular risk in Munduruku and Kayabi Indians of Amazonia. Environmental Research 97: 209-219.

Downing, J.A. 2010. Emerging global role of small lakes and ponds: Little things mean a lot. Limnetica 29: 9-23.

Downing, J.A., Y.T. Prairie, J.J. Cole, C.M. Duarte, L.J. Tranvik, R.G. Striegl, and J.J. Middelburg. 2006. The global abundance and size distribution of lakes, ponds, and impoundments. Limnology and Oceanography 51: 2388-2397.

Driscoll, C.T., C.Y. Chen, C.R. Hammerschmidt, R.P. Mason, C.C. Gilmour, E.M. Sunderland, and C.H. Lamborg. 2012. Nutrient 
supply and mercury dynamics in marine ecosystems: A conceptual model. Environmental Research 119: 118-131.

Driscoll, C.T., R.P. Mason, H.M. Chan, D.J. Jacob, and N. Pirrone. 2013. Mercury as a global pollutant: sources, pathways, and effects. Environmental Science and Technology 47: 4967-4983.

Duarte, E.C., and C.J. Fontes. 2002. Association between reported annual gold-mining extraction and incidence of malaria in Mato Gasso-Brazil, 1985-1996. Revista da Sociedade Brasileira de Medicina Tropical 35: 665-668.

Eagles-Smith, C.A., and J.T. Ackerman. 2014. Mercury bioaccumulation in estuarine wetland fishes: Evaluating habitats and risk to coastal wildlife. Environmental Pollution 193: 147-155.

Eagles-Smith, C.A., T.H. Suchanek, A.E. Colwell, N.L. Anderson, and P.B. Moyle. 2008. Changes in fish diets and food web mercury bioaccumulation induced by an invasive planktivorous fish. Ecological Applications 18: A213-A226.

Eagles-Smith, C.A., J.T. Ackerman, J. Yee, and T.L. Adelsbach. 2009. Mercury demethylation in waterbird livers: Dose-response thresholds and differences among species. Environmental Toxicology and Chemistry 28: 568-577.

Eagles-Smith, C.A., J.T. Ackerman, J.J. Willacker, M.T. Tate, M.A. Lutz, J.A. Fleck, and C.F. Pritz. 2016a. Spatial and temporal patterns of mercury concentrations in freshwater fish across the Western United States and Canada. Science of the Total Environment 568: 1171-1184.

Eagles-Smith, C.A., G. Herring, B. Johnson, and R. Graw. 2016b. Conifer density within lake catchments predicts fish mercury concentrations in remote subalpine lakes. Environmental Pollution 212: 279-289.

Ehrenfeld, J.G. 2003. Effects of exotic plant invasions on soil nutrient cycling processes. Ecosystems 6: 503-523.

Ehret, G.B., P.B. Munroe, K.M. Rice, M. Bochud, A.D. Johnson, D.I. Chasman, A.V. Smith, M.D. Tobin, et al. 2011. Genetic variants in novel pathways influence blood pressure and cardiovascular disease risk. Nature 478: 103-109.

Engstrom, K., S. Ameer, L. Bernaudat, G. Drasch, J. Baeuml, S. Skerfving, and K. Broberg. 2013. Polymorphisms in genes encoding potential mercury transporters and urine mercury concentrations in populations exposed to mercury vapor from gold mining. Environmental Health Perspectives 121: 85-91.

Essington, T.E., and J.N. Houser. 2003. The effect of whole-lake nutrient enrichment on mercury concentration in age-1 yellow perch. Transactions of the American Fisheries Society 132: 57-68.

Essington, T.E., A.H. Beaudreau, and J. Wiedenmann. 2006. Fishing through marine food webs. Proceedings of the National Academy of Sciences USA 103: 3171-3175.

Evans, D.O., and D.H. Loftus. 1987. Colonization of Inland Lakes in the Great-Lakes region by rainbow smelt, Osmerus-Mordaxtheir fresh-water niche and effects on indigenous fishes. Canadian Journal of Fisheries and Aquatic Sciences 44: 249-266.

Evans, R.D., N.M. Grochowina, N. Basu, E.M. O'Connor, B.E. Hickie, K. Rouvinen-Watt, and H.M. Chan. 2016. Uptake of selenium and mercury by captive mink: Results of a controlled feeding experiment. Chemosphere 144: 1582-1588.

Evers, D.C., L.J. Savoy, C.R. DeSorbo, D.E. Yates, W. Hanson, K.M. Taylor, and J. Fair. 2008. Adverse effects from environmental mercury loads on breeding common loons. Ecotoxicology 17: 69-81.

Fallacara, D.M., R.S. Halbrook, and J.B. French. 2011. Toxic effects of dietary methylmercury on immune function and hematology in american kestrels (Falco sparverius). Environmental Toxicology and Chemistry 30: 1320-1327.

Feng, X.B., P. Li, G.L. Qiu, S. Wang, G.H. Li, L.H. Shang, and X.W. Fu. 2008. Human exposure to methylmercury through rice intake in mercury mining areas, guizhou province, china. Environmental Science and Technology 42: 326-332.

Ficke, A.D., C.A. Myrick, and L.J. Hansen. 2007. Potential impacts of global climate change on freshwater fisheries. Reviews in Fish Biology and Fisheries 17: 581-613.

Fischer, C., A. Fredriksson, and P. Eriksson. 2008. Neonatal coexposure to low doses of an ortho-PCB (PCB 153) and methyl mercury exacerbate defective developmental neurobehavior in mice. Toxicology 244: 157-165.

Franzin, W.G., B.A. Barton, R.A. Remnant, D.B. Wain, and S.J. Pagel. 1994. Range extension, present and potential distribution, and possible effects of rainbow smelt in Hudson Bay drainage waters of northwestern Ontario, Manitoba, and Minnesota. North American Journal of Fisheries Management 14: 65-76.

French, K.J., M.R. Anderson, D.A. Scruton, and L.J. Ledrew. 1998. Fish mercury levels in relation to characteristics of hydroelectric reservoirs in Newfoundland, Canada. Biogeochemistry 40: $217-233$.

Friedl, G., and A. Wuest. 2002. Disrupting biogeochemical cyclesconsequences of damming. Aquatic Sciences 64: 55-65.

Frouin, H., L.L. Loseto, G.A. Stern, M. Haulena, and P.S. Ross. 2012. Mercury toxicity in beluga whale lymphocytes: Limited effects of selenium protection. Aquatic Toxicology 109: 185-193.

Gadd, G.M. 2010. Metals, minerals and microbes: Geomicrobiology and bioremediation. Microbiology-Sgm 156: 609-643.

Gallagher, C.M., D.M. Smith, and J.R. Meliker. 2011. Total blood mercury and serum measles antibodies in US children, NHANES 2003-2004. Science of the Total Environment 410: 65-71.

Gallagher, C.M., D.M. Smith, M.G. Golightly, and J.R. Meliker. 2013. Total blood mercury and rubella antibody concentrations in US children aged 6-11 years, NHANES 2003-2004. Science of the Total Environment 442: 48-55.

Gao, J., and Y.S. Liu. 2011. Climate warming and land use change in Heilongjiang Province, Northeast China. Applied Geography 31: 476-482.

Gardner, R.M., J.F. Nyland, and E.K. Silbergeld. 2010a. Differential immunotoxic effects of inorganic and organic mercury species in vitro. Toxicology Letters 198: 182-190.

Gardner, R.M., J.F. Nyland, I.A. Silva, A.M. Ventura, J.M. de Souza, and E.K. Silbergeld. 2010b. Mercury exposure, serum antinuclear/antinucleolar antibodies, and serum cytokine levels in mining populations in Amazonian Brazil: A cross-sectional study. Environmental Research 110: 345-354.

Gbetoh, M.H., and M. Amyot. 2016. Mercury, hydroquinone and clobetasol propionate in skin lightening products in West Africa and Canada. Environmental Research 150: 403-410.

Geer, L.A., M.D. Persad, C.D. Palmer, A.J. Steuerwald, M. Dalloul, O. Abulafia, and P.J. Parsons. 2012. Assessment of prenatal mercury exposure in a predominately Caribbean immigrant community in Brooklyn, NY. Journal of Environmental Monitoring 14: 1035-1043.

Gentes, S., M. Monperrus, A. Legeay, R. Maury-Brachet, S. Davail, J.M. Andre, and R. Guyoneaud. 2013. Incidence of invasive macrophytes on methylmercury budget in temperate lakes: Central role of bacterial periphytic communities. Environmental Pollution 172: 116-123.

Gerrard, P.M., and V.L. St Louis. 2001. The effects of experimental reservoir creation on the bioaccumulation of methylmercury and reproductive success of tree swallows (Tachycineta bicolor). Environmental Science and Technology 35: 1329-1338.

Gibb, H., and K.G. O'Leary. 2014. Mercury exposure and health impacts among individuals in the artisanal and small-scale gold mining community: A comprehensive review. Environmental Health Perspectives 122: 667-672.

Gilmour, C.C., M. Podar, A.L. Bullock, A.M. Graham, S.D. Brown, A.C. Somenahally, and D.A. Elias. 2013. Mercury methylation 
by novel microorganisms from new environments. Environmental Science and Technology 47: 11810-11820.

Goodrich, J.M., N. Basu, A. Franzblau, and D.C. Dolinoy. 2013. Mercury biomarkers and DNA methylation among michigan dental professionals. Environmental and Molecular Mutagenesis 54: 195-203.

Goodrich, J.M., H.N. Chou, S.E. Gruninger, A. Franzblau, and N. Basu. 2016. Exposures of dental professionals to elemental mercury and methylmercury. Journal of Exposure Science \& Environmental Epidemiology 26: 78-85.

Goutte, A., C. Barbraud, D. Herzke, P. Bustamante, F. Angelier, S. Tartu, C. Clément-Chastel, B. Moe, et al. 2015. Survival rate and breeding outputs in a high Arctic seabird exposed to legacy persistent organic pollutants and mercury. Environmental Pollution 200: 1-9.

Grandjean, P., P. Weihe, V.W. Burse, L.L. Needham, E. StorrHansen, B. Heinzow, and R.F. White. 2001. Neurobehavioral deficits associated with $\mathrm{PCB}$ in 7-year-old children prenatally exposed to seafood neurotoxicants. Neurotoxicology and Teratology 23: 305-317.

Green, D.J., M. Duffy, D.M. Janz, K. McCullum, G. Carriere, and T.D. Jardine. 2016. Historical and contemporary patterns of mercury in a hydroelectric reservoir and downstream fishery: Concentration decline in water and fishes. Archives of Environmental Contamination and Toxicology 71: 157-170.

Gribble, M.O., R. Karimi, B.J. Feingold, J.F. Nyland, T.M. O'Hara, M.I. Gladyshev, and C.Y. Chen. 2016. Mercury, selenium and fish oils in marine food webs and implications for human health. Journal of the Marine Biological Association of the United Kingdom 96: 43-59.

Gundacker, C., G. Komamicki, P. Jagiello, A. Gencikova, N. Dahmen, K.J. Wittmann, and M. Gencik. 2007. Glutathione-Stransferase polymorphism, metallothionein expression, and mercury levels among students in Austria. Science of the Total Environment 385: 37-47.

Gundacker, C., K.J. Wittmann, M. Kukuckova, G. Komarnicki, I. Hikkel, and M. Gencik. 2009. Genetic background of lead and mercury metabolism in a group of medical students in Austria. Environmental Research 109: 786-796.

Ha, E., N. Basu, S. Bose-O’Reilly, J.G. Dorea, E. McSorley, M. Sakamoto, and H.M. Chan. 2017. Current progress on understanding the impact of mercury on human health. Environmental Research 152: 419-433.

Hanna, C.W., M.S. Bloom, W.P. Robinson, D. Kim, P.J. Parsons, F.S.V. Saal, and V.Y. Fujimoto. 2012. DNA methylation changes in whole blood is associated with exposure to the environmental contaminants, mercury, lead, cadmium and bisphenol A, in women undergoing ovarian stimulation for IVF. Human Reproduction 27: 1401-1410.

Harari, R., F. Harari, L. Gerhardsson, T. Lundh, S. Skerfving, U. Stromberg, and K. Broberg. 2012. Exposure and toxic effects of elemental mercury in gold-mining activities in Ecuador. Toxicology Letters 213: 75-82.

Havel, J.E., C.E. Lee, and M.J. Vander Zanden. 2005. Do reservoirs facilitate invasions into landscapes? BioScience 55: 518-525.

Hawley, D.M., K.K. Hallinger, and D.A. Cristol. 2009. Compromised immune competence in free-living tree swallows exposed to mercury. Ecotoxicology 18: 499-503.

Haxton, T.J., and C.S. Findlay. 2009. Variation in large-bodied fishcommunity structure and abundance in relation to watermanagement regime in a large regulated river. Journal of Fish Biology 74: 2216-2238.

Heinz, G.H., D.J. Hoffman, J.D. Klimstra, and K.R. Stebbins. 2012. A comparison of the teratogenicity of methylmercury and selenomethionine injected into bird eggs. Archives of Environmental Contamination and Toxicology 62: 519-528.
Henderson, B.L., M.M. Chumchal, R.W. Drenner, Y.C. Deng, P. Diaz, and W.H. Nowlin. 2012. Effects of fish on mercury contamination of macroinvertebrate communities of Grassland ponds. Environmental Toxicology and Chemistry 31: 870-876.

Herbert, E.R., P. Boon, A.J. Burgin, S.C. Neubauer, R.B. Franklin, M. Ardón, K.N. Hopfensperger, L.P.M. Lamers, et al. 2015. A global perspective on wetland salinization: Ecological consequences of a growing threat to freshwater wetlands. Ecosphere 6: $1-43$.

Herring, G., C.A. Eagles-Smith, J.T. Ackerman, D.E. Gawlik, and J.M. Beerens. 2013. Landscape factors and hydrology influence mercury concentrations in wading birds breeding in the Florida Everglades, USA. Science of the Total Environment 458: 637-646.

Hightower, J.M., and D. Moore. 2003. Mercury levels in high-end consumers of fish. Environmental Health Perspectives 111: 604-608.

Hilson, G., and C. Garforth. 2012. 'Agricultural Poverty' and the expansion of artisanal mining in sub-Saharan Africa: Experiences from southwest Mali and southeast Ghana. Population Research and Policy Review 31: 435-464.

Holeton, C., P.A. Chambers, and L. Grace. 2011. Wastewater release and its impacts on Canadian waters. Canadian Journal of Fisheries and Aquatic Sciences 68: 1836-1859.

Hooper, D.U., E.C. Adair, B.J. Cardinale, J.E. Byrnes, B.A. Hungate, K.L. Matulich, and M.I. O'Connor. 2012. A global synthesis reveals biodiversity loss as a major driver of ecosystem change. Nature 486: 105-108.

Hopkins, B.C., J.D. Willson, and W.A. Hopkins. 2013. Mercury exposure is associated with negative effects on turtle reproduction. Environmental Science and Technology 47: 2416-2422.

Hrabik, T.R., J.J. Magnuson, and A.S. McLain. 1998. Predicting the effects of rainbow smelt on native fishes in small lakes: Evidence from long-term research on two lakes. Canadian Journal of Fisheries and Aquatic Sciences 55: 1364-1371.

Hsu-Kim, H., C.S. Eckley, D. Achá, X. Feng, C.C. Gilmour, S. Jonsson, and C.P.J. Mitchell. 2018. Challenges and opportunities for managing aquatic mercury pollution in altered landscapes. Ambio. https://doi.org/10.1007/s13280-017-1006-7.

Hu, X.F., K.M. Eccles, and H.M. Chan. 2017. High selenium exposure lowers the odds ratios for hypertension, stroke, and myocardial infarction associated with mercury exposure among Inuit in Canada. Environment International 102: 200-206.

Huang, S.S.Y., A.B. Strathe, J.G. Fadel, M.L. Johnson, P.P. Lin, T.Y. Liu, and S.S.O. Hung. 2013. The interactive effects of selenomethionine and methylmercury on their absorption, disposition, and elimination in juvenile white sturgeon. Aquatic Toxicology 126: 274-282.

Hui, L.L., M.H.M. Chan, H.S. Lam, P.H.Y. Chan, K.M. Kwok, I.H.S. Chan, and T.F. Fok. 2016. Impact of fetal and childhood mercury exposure on immune status in children. Environmental Research 144: 66-72.

Huttenhower, C., D. Gevers, R. Knight, S. Abubucker, J.H. Badger, A.T. Chinwalla, H.H. Creasy, A.M. Earl, et al. 2012. Structure, function and diversity of the healthy human microbiome. Nature 486: 207-214.

Hylander, L.D., J. Grohn, M. Tropp, A. Vikstrom, H. Wolpher, E.D.E. Silva, and L.J. Oliveira. 2006. Fish mercury increase in Lago Manso, a new hydroelectric reservoir in tropical Brazil. Journal of Environmental Management 81: 155-166.

Ilback, N.G., P. Frisk, J. Tallkvist, I.L. Gadhasson, J. Blomberg, and G. Friman. 2008. Gastrointestinal uptake of trace elements are changed during the course of a common human viral (Coxsackievirus B3) infection in mice. Journal of Trace Elements in Medicine and Biology 22: 120-130. 
IPCC. 2014. Climate Change 2014: Synthesis Report. Contribution of working groups I, II and III to the fifth assessment report of the intergovernmental panel on climate change. IPCC, Geneva, Switzerland.

Janse, J.H., J.J. Kuiper, M.J. Weijters, E.P. Westerbeek, M. Jeuken, M. Bakkenes, and J.T.A. Verhoeven. 2015. GLOBIO-Aquatic, a global model of human impact on the biodiversity of inland aquatic ecosystems. Environmental Science \& Policy 48: 99-114.

Jennings, S., G.D. Stentiford, A.M. Leocadio, K.R. Jeffery, J.D. Metcalfe, I. Katsiadaki, and D.W. Verner-Jeffreys. 2016. Aquatic food security: Insights into challenges and solutions from an analysis of interactions between fisheries, aquaculture, food safety, human health, fish and human welfare, economy and environment. Fish and Fisheries 17: 893-938.

Johnson, C. 1999. Elemental mercury use in religious and ethnic practices in Latin American and Caribbean communities in New York City. Population and Environment 20: 443-453.

Johnson, B.M., J.M. Lepak, and B.A. Wolff. 2015. Effects of prey assemblage on mercury bioaccumulation in a piscivorous sport fish. Science of the Total Environment 506: 330-337.

Johnston, T.A., W.C. Leggett, R.A. Bodaly, and H.K. Swanson. 2003. Temporal changes in mercury bioaccumulation by predatory fishes of boreal lakes following the invasion of an exotic forage fish. Environmental Toxicology and Chemistry 22: 2057-2062.

Jones, T.A., M.M. Chumchal, R.W. Drenner, G.N. Timmins, and W.H. Nowlin. 2013. Bottom-up nutrient and top-down fish impacts on insect-mediated mercury flux from aquatic ecosystems. Environmental Toxicology and Chemistry 32: 612-618.

Kamman, N.C., N.M. Burgess, C.T. Driscoll, H.A. Simonin, M.W. Goodale, J.C. Linehan, and D.A. Scruton. 2005. Mercury in freshwater fish of Northeast North America-a geographic perspective based on fish tissue monitoring databases. Ecotoxicology 14: 163-180.

Karagas, M.R., A.L. Choi, E. Oken, M. Horvat, R. Schoeny, E. Kamai, and S. Korrick. 2012. Evidence on the human health effects of low-level methylmercury exposure. Environmental Health Perspectives 120: 799-806.

Karimi, R., T.P. Fitzgerald, and N.S. Fisher. 2012. A quantitative synthesis of mercury in commercial seafood and implications for exposure in the United States. Environmental Health Perspectives 120: 1512-1519.

Karimi, R., S. Silbernagel, N.S. Fisher, and J.R. Meliker. 2014. Elevated blood $\mathrm{Hg}$ at recommended seafood consumption rates in adult seafood consumers. International Journal of Hygiene and Environmental Health 217: 758-764.

Karimi, R., C.Y. Chen, and C.L. Folt. 2016a. Comparing nearshore benthic and pelagic prey as mercury sources to lake fish: the importance of prey quality and mercury content. Science of the Total Environment 565: 211-221.

Karimi, R., C. Vacchi-Suzzi, and J.R. Meliker. 2016b. Mercury exposure and a shift toward oxidative stress in avid seafood consumers. Environmental Research 146: 100-107.

Kasper, D., B.R. Forsberg, J.H.F. Amaral, R.P. Leitao, S.S. PyDaniel, W.R. Bastos, and O. Malm. 2014. Reservoir stratification affects methylmercury levels in river water, plankton, and fish downstream from Balbina Hydroelectric Dam, Amazonas, Brazil. Environmental Science and Technology 48: 1032-1040.

Kau, A.L., P.P. Ahern, N.W. Griffin, A.L. Goodman, and J.I. Gordon. 2011. Human nutrition, the gut microbiome and the immune system. Nature 474: 327-336.

Khan, M.A.K., and F.Y. Wang. 2009. Mercury-selenium compounds and their toxicological significance: Toward a molecular understanding of the mercury-selenium antagonism. Environmental Toxicology and Chemistry 28: 1567-1577.
Kidd, K.A., M.J. Paterson, R.H. Hesslein, D.C.G. Muir, and R.E. Hecky. 1999. Effects of northern pike (Esox lucius) additions on pollutant accumulation and food web structure, as determined by delta $\mathrm{C}-13$ and delta $\mathrm{N}-15$, in a eutrophic and an oligotrophic lake. Canadian Journal of Fisheries and Aquatic Sciences 56: 2193-2202.

Klaper, R., C.B. Rees, P. Drevnick, D. Weber, M. Sandheinrich, and M.J. Carvan. 2006. Gene expression changes related to endocrine function and decline in reproduction in fathead minnow (Pimephales promelas) after dietary methylmercury exposure. Environmental Health Perspectives 114: 1337-1343.

Kruzikova, K., L. Dusek, J. Jarkovsky, M. Hejtmanek, J. Vostradovsky, G. Poleszczuk, and Z. Svobodova. 2011. Long-term monitoring of mercury content in fish from the zelivka reservoirsyndrom of newly filled reservoir. International Journal of Electrochemical Science 6: 5956-5967.

Landler, L., M.S. Painter, B.H. Coe, P.W. Youmans, W.A. Hopkins, and J.B. Phillips. 2017. High levels of maternally transferred mercury disrupt magnetic responses of snapping turtle hatchlings (Chelydra serpentina). Environmental Pollution 11: 19-25.

Larson, J.H., R.P. Maki, B.C. Knights, and B.R. Gray. 2014. Can mercury in fish be reduced by water level management? Evaluating the effects of water level fluctuation on mercury accumulation in yellow perch (Perca flavescens). Ecotoxicology 23: $1555-1563$

Larsson, P., L. Collvin, L. Okla, and G. Meyer. 1992. Lake productivity and water chemistry as governors of the uptake of persistent pollutants in fish. Environmental Science and Technology 26: 346-352.

Lartey, M., F.D. Krampa, M. Abdul-Rahman, N.L. Quarcoo, P. Yamson, P.G. Hagan, and A.A. Adjei. 2017. Use of skinlightening products among selected urban communities in Accra, Ghana. International Journal of Dermatology 56: 32-39.

Lauber, T.B., N.A. Connelly, J. Niederdeppe, and B.A. Knuth. 2017. Urban anglers in the Great Lakes region: Fish consumption patterns, influences, and responses to advisory messages. Science of the Total Environment 590: 495-501.

Lavoie, R.A., T.D. Jardine, M.M. Chumchal, K.A. Kidd, and L.M. Campbell. 2013. Biomagnification of mercury in aquatic food webs: A worldwide meta-analysis. Environmental Science and Technology 47: 13385-13394.

Lee, B.E., Y.C. Hong, H. Park, M. Ha, B.S. Koo, N. Chang, and E.H. Ha. 2010. Interaction between GSTM1/GSTT1 polymorphism and blood mercury on birth weight. Environmental Health Perspectives 118: 437-442.

Lepak, J.M., K.-D. Kinzli, E.R. Fetherman, W.M. Pate, A.G. Hansen, E.I. Gardunio, C. Nathan Cathcart, W.L. Stacy, et al. 2012. Manipulation of growth to reduce mercury concentrations in sport fish on a whole-system scale. Canadian Journal of Fisheries and Aquatic Sciences 69: 122-135.

Lepak, R.F., D.P. Krabbenhoft, J.M. Ogorek, M.T. Tate, H.A. Bootsma, and J.P. Hurley. 2015. Influence of CladophoraQuagga Mussel Assemblages on Nearshore methylmercury production in Lake Michigan. Environmental Science and Technology 49: 7606-7613.

Levy, S.B., and B. Marshall. 2004. Antibacterial resistance worldwide: causes, challenges and responses. Nature Medicine 10: S122-S129.

Lewis, C.A., D.A. Cristol, J.P. Swaddle, C.W. Varian-Ramos, and P. Zwollo. 2013. Decreased immune response in zebra finches exposed to sublethal doses of mercury. Archives of Environmental Contamination and Toxicology 64: 327-336.

Li, M., B.H. Wang, M.H. Zhang, M. Rantalainen, S.Y. Wang, H.K. Zhou, and L.P. Zhao. 2008. Symbiotic gut microbes modulate human metabolic phenotypes. Proceedings of the National Academy of Sciences USA 105: 2117-2122. 
Li, Y.F., Z.Q. Dong, C.Y. Chen, B. Li, Y.X. Gao, L.Y. Qu, and Z.F. Chai. 2012. Organic selenium supplementation increases mercury excretion and decreases oxidative damage in long-term mercury-exposed residents from Wanshan, China. Environmental Science and Technology 46: 11313-11318.

Li, S., L. Zhou, H. Wang, M. Xiong, Z. Yang, J. Hu, Y. Liang, and J. Chang. 2013. Short-term impact of reservoir impoundment on the patterns of mercury distribution in a subtropical aquatic ecosystem, Wujiang River, southwest China. Environmental Science and Pollution Research 20: 4396-4404.

Li, J., Q. Zhou, G.L. Yuan, X.G. He, and P. Xie. 2015. Mercury bioaccumulation in the food web of Three Gorges Reservoir (China): Tempo-spatial patterns and effect of reservoir management. Science of the Total Environment 527: 203-210.

Li, L.G., Y. Xia, and T. Zhang. 2017. Co-occurrence of antibiotic and metal resistance genes revealed in complete genome collection. ISME Journal 11: 651-662.

Llop, S., M.J. Lopez-Espinosa, M. Murcia, M. Alvarez-Pedrerol, J. Vioque, X. Aguinagalde, J. Julvez, J.J. Aurrekoetxea, et al. 2015. Synergism between exposure to mercury and use of iodine supplements on thyroid hormones in pregnant women. Environmental Research 138: 298-305.

Lloyd, N.A., S.E. Janssen, J.R. Reinfelder, and T. Barkay. 2016. Coselection of mercury and multiple antibiotic resistances in bacteria exposed to mercury in the Fundulus heteroclitus Gut Microbiome. Current Microbiology 73: 834-842.

Lopes, A.S., J.G. Ferreira, C. Vale, and J. Johansen. 2017. The mass balance of production and consumption: Supporting policymakers for aquatic food security. Estuarine, Coastal and Shelf Science 188: 212-223.

Luque-Garcia, J.L., P. Cabezas-Sanchez, D.S. Anunciacao, and C. Camara. 2013. Analytical and bioanalytical approaches to unravel the selenium-mercury antagonism: A review. Analytica Chimica Acta 801: 1-13.

Mack, R.N., D. Simberloff, W.M. Lonsdale, H. Evans, M. Clout, and F.A. Bazzaz. 2000. Biotic invasions: Causes, epidemiology, global consequences, and control. Ecological Applications 10: 689-710.

Madan, J.C., S.F. Farzan, P.L. Hibberd, and M.R. Karagas. 2012. Normal neonatal microbiome variation in relation to environmental factors, infection and allergy. Current Opinion in Pediatrics 24: 753-759.

Magnuson, J.J., K.E. Webster, R.A. Assel, C.J. Bowser, P.J. Dillon, J.G. Eaton, and F.H. Quinn. 1997. Potential effects of climate changes on aquatic systems: Laurentian Great Lakes and Precambrian Shield Region. Hydrological Processes 11: 825-871.

Mahaffey, K.R., R.P. Clickner, and R.A. Jeffries. 2009. Adult women's blood mercury concentrations vary regionally in the United States: Association with patterns of fish consumption (NHANES 1999-2004). Environmental Health Perspectives 117: 47-53.

Martin-Doimeadios, R.C.R., R. Mateo, and M. Jimenez-Moreno. 2017. Is gastrointestinal microbiota relevant for endogenous mercury methylation in terrestrial animals? Environmental Research 152: 454-461.

Masur, L.C. 2011. A review of the use of mercury in historic and current ritualistic and spiritual practices. Alternative Medicine Review 16: 314-320.

Mauro, J.B.N., J.R.D. Guimaraes, H. Hintelmann, C.J. Watras, E.A. Haack, and S.A. Coelho-Souza. 2002. Mercury methylation in macrophytes, periphyton, and water-comparative studies with stable and radio-mercury additions. Analytical and Bioanalytical Chemistry 374: 983-989.

McClanahan, T., E.H. Allison, and J.E. Cinner. 2015. Managing fisheries for human and food security. Fish and Fisheries 16: 78-103.
McKelvey, W., N. Jeffery, N. Clark, D. Kass, and P.J. Parsons. 2011. Population-Based Inorganic Mercury Biomonitoring and the Identification of Skin Care Products as a Source of Exposure in New York City. Environmental Health Perspectives 119: 203-209.

McNickle, G.G., M.D. Rennie, and W.G. Sprules. 2006. Changes in benthic invertebrate communities of South Bay, Lake Huron following invasion by zebra mussels (Dreissena polymorpha), and potential effects on lake whitefish (Coregonus clupeaformis) diet and growth. Journal of Great Lakes Research 32: 180-193.

Meredith, M.M., E.M. Parry, J.A. Guay, N.O. Markham, G.R. Danner, K.A. Johnson, and F.A. Fekete. 2012. Concomitant antibiotic and mercury resistance among gastrointestinal microflora of feral brook trout, Salvelinus fontinalis. Current Microbiology 65: 575-582.

Mergler, D., H.A. Anderson, L.H.M. Chan, K.R. Mahaffey, M. Murray, M. Sakamoto, and A.H. Stern. 2007. Methylmercury exposure and health effects in humans: A worldwide concern. Ambio 36: 3-11. https://doi.org/10.1579/0044-7447(2007)36\% 5B3:MEAHEI\%5D2.0.CO;2.

Meyer, E., C.A. Eagles-Smith, D. Sparling, and S. Blumenshine. 2014. Mercury exposure associated with altered plasma thyroid hormones in the declining western pond turtle (Emys marmorata) from California mountain streams. Environmental Science and Technology 48: 2989-2996.

Meyerson, L.A., K. Saltonstall, L. Windham, E. Kiviat, and S. Findlay. 2000. A comparison of Phragmites australis in freshwater and brackish marsh environments in North America. Wetlands Ecology and Management 8: 89-103.

Mitchell, K.J. 2011. The genetics of neurodevelopmental disease. Current Opinion in Neurobiology 21: 197-203.

Modabbernia, A., E. Velthorst, and A. Reichenberg. 2017. Environmental risk factors for autism: An evidence-based review of systematic reviews and meta-analyses. Molecular Autism 8: 13.

Monastero, R.N., R. Karimi, J.F. Nyland, J. Harrington, K. Levine, and J. Meliker. 2017. Mercury exposure, serum antinuclear antibodies, and serum cytokine levels in the Long Island Study of Seafood Consumption: A cross-sectional study in NY, USA. Environmental Research 156: 334-340.

Monson, B.A., D.F. Staples, S.P. Bhavsar, T.M. Holsen, C.S. Schrank, S.K. Moses, D.J. McGoldrick, S.M. Backus, et al. 2011. Spatiotemporal trends of mercury in walleye and largemouth bass from the Laurentian Great Lakes region. Ecotoxicology 20: 1555-1567.

Moreno-Mateos, D., M.E. Power, F.A. Comin, and R. Yockteng. 2012. Structural and functional loss in restored wetland ecosystems. PLoS Biology 10: e1001247.

Motts, J.A., D.L. Shirley, E.K. Silbergeld, and J.F. Nyland. 2014. Novel biomarkers of mercury-induced autoimmune dysfunction: A cross-sectional study in Amazonian Brazil. Environmental Research 132: 12-18.

Mozaffarian, D., and E.B. Rimm. 2006. Fish intake, contaminants, and human health-evaluating the risks and the benefits. JamaJournal of the American Medical Association 296: 1885-1899.

Muegge, B.D., J. Kuczynski, D. Knights, J.C. Clemente, A. Gonzalez, L. Fontana, and J.I. Gordon. 2011. Diet Drives convergence in gut microbiome functions across mammalian phylogeny and within humans. Science 332: 970-974.

Nakagawa, R., Y. Yumita, and M. Hiromoto. 1997. Total mercury intake from fish and shellfish by Japanese people. Chemosphere 35: 2909-2913.

Newby, C.A., D.M. Riley, and T.O. Leal-Almeraz. 2006. Mercury use and exposure among Santeria practitioners: Religious versus folk practice in Northern New Jersey, USA. Ethnicity \& Health 11: 287-306. 
Niederdeppe, J., N.A. Connelly, T.B. Labuer, and B.A. Knuth. 2015. Using theory to identify beliefs associated with intentions to follow fish consumption advisories among anglers living in the Great Lakes Region. Risk Analysis 35: 1996-2008.

Nilsson, C. 2005. The future of large dams: Dealing with the social, environmental and political costs. Nature 435: 1031.

Nilsson, C., and K. Berggren. 2000. Alterations of riparian ecosystems caused by river regulation. BioScience 50: 783-792.

Nriagu, J., N. Basu, and S. Charles. 2012. Environmental justice: The mercury connection. In Mercury in the environment: Pattern and process, ed. Bank. Berkeley, CA: University of California Press.

Nyland, J.F., M. Fillion, F. Barbosa, D.L. Shirley, C. Chine, M. Lemire, and E.K. Silbergeld. 2011. Biomarkers of methylmercury exposure immunotoxicity among fish consumers in Amazonian Brazil. Environmental Health Perspectives 119: $1733-1738$.

Nyland, J.F., D. Fairweather, D.L. Shirley, S.E. Davis, N.R. Rose, and E.K. Silbergeld. 2012. Low-dose inorganic mercury increases severity and frequency of chronic coxsackievirus-induced autoimmune myocarditis in mice. Toxicological Sciences 125: 134-143.

Obrist, D., J.L. Kirk, L. Zhang, E.M. Sunderland, M. Jiskra, and N.E. Selin. 2018. A review of global environmental mercury processes in response to human and natural perturbations: Changes of emissions, climate, and land use. Ambio. https:// doi.org/10.1007/s13280-017-1004-9.

Occhipinti-Ambrogi, A., and D. Savini. 2003. Biological invasions as a component of global change in stressed marine ecosystems. Marine Pollution Bulletin 46: 542-551.

Oken, E., J.S. Radesky, R.O. Wright, D.C. Bellinger, C.J. Amarasiriwardena, K.P. Kleinman, and M.W. Gillman. 2008. Maternal fish intake during pregnancy, blood mercury levels, and child cognition at age 3 years in a US cohort. American Journal of Epidemiology 167: 1171-1181.

Olden, J.D., and R.J. Naiman. 2010. Incorporating thermal regimes into environmental flows assessments: Modifying dam operations to restore freshwater ecosystem integrity. Freshwater Biology 55: 86-107.

Ouedraogo, O., J. Chetelat, and M. Amyot. 2015. Bioaccumulation and trophic transfer of mercury and selenium in african subtropical fluvial reservoirs food webs (Burkina Faso). PLoS ONE 10: $\mathrm{e} 0123048$

Pal, C., J. Bengtsson-Palme, E. Kristiansson, and D.G.J. Larsson. 2015. Co-occurrence of resistance genes to antibiotics, biocides and metals reveals novel insights into their co-selection potential. BMC Genomics 16: 964.

Parajuli, R.P., J.M. Goodrich, H.N. Chou, S.E. Gruninger, D.C. Dolinoy, A. Franzblau, and N. Basu. 2016. Genetic polymorphisms are associated with hair, blood, and urine mercury levels in the American Dental Association (ADA) study participants. Environmental Research 149: 247-258.

Paranjape, A.R., and B. Hall. 2017. Recent advances in the study of mercury methylation in aquatic systems. FACETS 2: 85-119.

Pauly, D., V. Christensen, J. Dalsgaard, R. Froese, and F. Torres. 1998. Fishing down marine food webs. Science 279: 860-863.

Pauly, D., R. Watson, and J. Alder. 2005. Global trends in world fisheries: Impacts on marine ecosystems and food security. Philosophical Transactions of the Royal Society B-Biological Sciences 360: 5-12.

Penglase, S., K. Hamre, and S. Ellingsen. 2014. Selenium and Mercury have a synergistic negative effect on fish reproduction. Aquatic Toxicology 149: 16-24.

Perez, H., E.C. Sullivan, K. Michael, and R. Harris. 2012. Fish consumption and advisory awareness among the philadelphia asian community: A pilot study. Journal of Environmental Health 74: 24-28.
Perron, T., J. Chetelat, J. Gunn, B.E. Beisner, and M. Amyot. 2014. Effects of experimental thermocline and oxycline deepening on methylmercury bioaccumulation in a Canadian Shield Lake. Environmental Science and Technology 48: 2626-2634.

Petchey, O.L., P.T. McPhearson, T.M. Casey, and P.J. Morin. 1999. Environmental warming alters food-web structure and ecosystem function. Nature 402: 69-72.

Phalan, B., A. Balmford, R.E. Green, and J.P.W. Scharlemann. 2011. Minimising the harm to biodiversity of producing more food globally. Food Policy 36: S62-S71.

Phillips, B.L., G.P. Brown, and R. Shine. 2003. Assessing the potential impact of cane toads on Australian snakes. Conservation Biology 17: 1738-1747.

Pickhardt, P.C., C.L. Folt, C.Y. Chen, B. Klaue, and J.D. Blum. 2002. Algal blooms reduce the uptake of toxic methylmercury in freshwater food webs. Proceedings of the National Academy of Sciences USA 99: 4419-4423.

Pilsner, J.R., A.L. Lazarus, D.H. Nam, R.J. Letcher, C. Sonne, R. Dietz, and N. Basu. 2010. Mercury-associated DNA hypomethylation in polar bear brains via the LUminometric Methylation Assay: a sensitive method to study epigenetics in wildlife. Molecular Ecology 19: 307-314.

Pimentel, D., L. Lach, R. Zuniga, and D. Morrison. 2000. Environmental and economic costs of nonindigenous species in the United States. BioScience 50: 53-65.

Pimentel, D., S. McNair, J. Janecka, J. Wightman, C. Simmonds, C. O'Connell, and T. Tsomondo. 2001. Economic and environmental threats of alien plant, animal, and microbe invasions. Agriculture, Ecosystems \& Environment 84: 1-20.

Pimentel, D., R. Zuniga, and D. Morrison. 2005. Update on the environmental and economic costs associated with alien-invasive species in the United States. Ecological Economics 52: 273-288.

Poff, N.L., J.D. Olden, D.M. Merritt, and D.M. Pepin. 2007. Homogenization of regional river dynamics by dams and global biodiversity implications. Proceedings of the National Academy of Sciences USA 104: 5732-5737.

Polito, M.J., R.L. Brasso, W.Z. Trivelpiece, N. Karnovsky, W.P. Patterson, and S.D. Emslie. 2016. Differing foraging strategies influence mercury $(\mathrm{Hg})$ exposure in an Antarctic penguin community. Environmental Pollution 218: 196-206.

Porvari, P. 1998. Development of fish mercury concentrations in Finnish reservoirs from 1979 to 1994. Science of the Total Environment 213: 279-290.

Postel, S.L., G.C. Daily, and P.R. Ehrlich. 1996. Human appropriation of renewable fresh water. Science 271: 785-788.

Power, M., G.M. Klein, K. Guiguer, and M.K.H. Kwan. 2002. Mercury accumulation in the fish community of a sub-Arctic lake in relation to trophic position and carbon sources. Journal of Applied Ecology 39: 819-830.

Rahel, F.J., and J.D. Olden. 2008. Assessing the effects of climate change on aquatic invasive species. Conservation Biology 22: 521-533.

Ralston, N.V.C., and L.J. Raymond. 2010. Dietary selenium's protective effects against methylmercury toxicity. Toxicology 278: 112-123.

Ralston, N.V.C., C.R. Ralston, and L.J. Raymond. 2016. Selenium health benefit values: Updated criteria for mercury risk assessments. Biological Trace Element Research 171: 262-269.

Razavi, N.R., M.Z. Qu, B.S. Jin, W.W. Ren, Y.X. Wang, and L.M. Campbell. 2014. Mercury biomagnification in subtropical reservoir fishes of eastern China. Ecotoxicology 23: 133-146.

Rice, D.C. 2008. Overview of modifiers of methylmercury neurotoxicity: Chemicals, nutrients, and the social environment. Neurotoxicology 29: 761-766.

Richardson, J.S., and S. Beraud. 2014. Effects of riparian forest harvest on streams: A meta-analysis. Journal of Applied Ecology 51: $1712-1721$. 
Richardson, D.M., P. Pysek, M. Rejmanek, M.G. Barbour, F.D. Panetta, and C.J. West. 2000. Naturalization and invasion of alien plants: concepts and definitions. Diversity and Distributions 6: 93-107.

Riley, D.M., C.A. Newby, T.O. Leal-Almeraz, and V.M. Thomas. 2001. Assessing elemental mercury vapor exposure from cultural and religious practices. Environmental Health Perspectives 109: 779-784.

Roegge, C.S., V.C. Wang, B.E. Powers, A.Y. Klintsova, S. Villareal, W.T. Greenough, and S.L. Schantz. 2004. Motor impairment in rats exposed to $\mathrm{PCBs}$ and methylmercury during early development. Toxicological Sciences 77: 315-324.

Rosenberg, D.M., P. McCully, and C.M. Pringle. 2000. Global-scale environmental effects of hydrological alterations: Introduction. BioScience 50: 746-751.

Rothenberg, S.E., S. Keiser, N.J. Ajami, M.C. Wong, J. Gessell, J.F. Petrosino, and A. Johs. 2016. The role of gut microbiota in fetal methylmercury exposure: Insights from a pilot study. Toxicological Letters 242: 60-67.

Rowland, I.R., P. Grasso, and M.J. Davies. 1975. Methylation of mercuric-chloride by human intestinal bacteria. Experientia 31: 1064-1065.

Rowland, I.R., R.D. Robinson, and R.A. Doherty. 1984. Effects of diet on mercury metabolism and excretion in mice given methylmercury-role of Gut Flora. Archives of Environmental Health 39: 401-408.

Rudd, J.W., and M.A. Turner. 1983. The English-Wabigoon River system: V. mercury and selenium bioaccumulation as a function of aquatic primary productivity. Canadian Journal of Fisheries and Aquatic Sciences 40: 2251-2259.

Sabo, J.L., T. Sinha, L.C. Bowling, G.H.W. Schoups, W.W. Wallender, M.E. Campana, and E.E. Wohl. 2010. Reclaiming freshwater sustainability in the Cadillac Desert. Proceedings of the National Academy of Sciences USA 107: 21263-21270.

Sahagian, D. 2000. Global physical effects of anthropogenic hydrological alterations: sea level and water redistribution. Global and Planetary Change 25: 39-48.

Sampaio da Silva, D., M. Lucotte, S. Paquet, and R. Davidson. 2009. Influence of ecological factors and of land use on mercury levels in fish in the Tapajos River basin, Amazon. Environmental Research 109: 432-446.

Scheuhammer, A.M., and M.B. Sandheinrich. 2008. Recent advances in the toxicology of methylmercury in wildlife. Ecotoxicology 17: 67-68.

Selin, N.E., E.M. Sunderland, C.D. Knightes, and R.A. Mason. 2010. Sources of mercury exposure for US seafood consumers: Implications for policy. Environmental Health Perspectives 118: 137-143.

Selin, H., S.E. Keane, S. Wang, N.E. Selin, K. Davis, and D.Bally. 2018. Linking science and policy to support the implementation of the Minamata Convention on Mercury. Ambio. https://doi.org/ 10.1007/s13280-017-1003-x.

Shafroth, P.B., J.R. Cleverly, T.L. Dudley, J.P. Taylor, C. Van Riper, E.P. Weeks, and J.N. Stuart. 2005. Control of tamarix in the Western United States: Implications for water salvage, wildlife use, and riparian restoration. Environmental Management 35: 231-246.

Sheehan, M.C., T.A. Burke, A. Navas-Acien, P.N. Breysse, J. McGready, and M.A. Fox. 2014. Global methylmercury exposure from seafood consumption and risk of developmental neurotoxicity: a systematic review. Bulletin of the World Health Organization 92: 254-269.

Silbergeld, E.K., J.B. Sacci, and A.F. Azad. 2000. Mercury exposure and murine response to Plasmodium yoelii infection and immunization. Immunopharmacology and Immunotoxicology 22: $685-695$.
Silbergeld, E.K., D. Nash, C. Trevant, G.T. Strickland, J.M. de Souza, and R.S. da Silva. 2002. Mercury exposure and malaria prevalence among gold miners in Pará, Brazil. Revista da Sociedade Brasileira de Medicina Tropical 35: 421-429.

Silbergeld, E., R. Gardner, J.M. De Souza, A.M. Ventura, and J. Nyland. 2010. Immunotoxic effects of mercury compounds in humans: Concordance of in vitro and in vivo studies. Toxicology Letters 196: S202-S202.

Silva, I.A., J.F. Nyland, A. Gorman, A. Perisse, A.M. Ventura, E. Santos, and E.K. Silbergeld. 2004. Mercury exposure, malaria, and serum antinuclear/antinucleolar antibodies in Amazon populations in Brazil: a cross-sectional study. Environmental Health 3: 1-12.

Silva, I.A., M. El Nabawi, D. Hoover, and E.K. Silbergeld. 2005a. Prenatal $\mathrm{HgCl}_{2}$ exposure in BALB/c mice: gender-specific effects on the ontogeny of the immune system. Developmental and Comparative Immunology 29: 171-183.

Silva, I.A., J. Graber, J.F. Nyland, and E. Silbergeld. 2005b. In vitro $\mathrm{HgCl} 2$ exposure of immune cells at different stages of maturation: Effects on phenotype and function. Environmental Research 98: 341-348.

Skurnik, D., R. Ruimy, D. Ready, E. Ruppe, C. Bernède-Bauduin, F. Djossou, D. Guillemot, G.B. Pier, et al. 2010. Is exposure to mercury a driving force for the carriage of antibiotic resistance genes? Journal of Medical Microbiology 59: 804-807.

Slotton, D.G., J.E. Reuter, and C.R. Goldman. 1995. Mercury uptake patterns of biota in a seasonally anoxic northern california reservoir. Water, Air, and Soil pollution 80: 841-850.

Snodgrass, J., C.H. Jagoe, A.L. Bryan Jr., H.A. Brant, and J. Burger. 2000. Effects of trophic status and wetland morphology, hydroperiod, and water chemistry on mercury concentrations in fish. Canadian Journal of Fisheries and Aquatic Sciences 57: 171-180.

Sorensen, J.A., L.W. Kallemeyn, and M. Sydor. 2005. Relationship between mercury accumulation in young-of-the-year yellow perch and water-level fluctuations. Environmental Science and Technology 39: 9237-9243.

Sormo, E.G., T.M. Ciesielski, I.B. Overjordet, S. Lierhagen, G.S. Eggen, T. Berg, and B.M. Jenssen. 2011. Selenium moderates mercury toxicity in free-ranging freshwater fish. Environmental Science and Technology 45: 6561-6566.

Steckling, N., S. Boese-O'Reilly, C. Gradel, K. Gutschmidt, E. Shinee, E. Altangerel, and C. Hornberg. 2011. Mercury exposure in female artisanal small-scale gold miners (ASGM) in Mongolia: An analysis of human biomonitoring (HBM) data from 2008. Science of the Total Environment 409: 994-1000.

Steuerwald, U., P. Weihe, P.J. Jorgensen, K. Bjerve, J. Brock, B. Heinzow, and P. Grandjean. 2000. Maternal seafood diet, methylmercury exposure, and neonatal neurologic function. Journal of Pediatrics 136: 599-605.

Stewart, P.W., J. Reihman, E.I. Lonky, T.J. Darvill, and J. Pagano. 2003. Cognitive development in preschool children prenatally exposed to PCBs and MeHg. Neurotoxicology and Teratology 25: 11-22.

Stratton, K., A. Gable, and M.C. McCormick (eds.). 2001. Immunization safety review: Thimerosal-containing vaccines and neurodevelopmental disorders. Washington, DC: National Acadamies Press.

Streets, D.G., H.M. Horowitz, D.J. Jacob, Z. Lu, L. Levin, A.F.H. Ter Schure, and E.M. Sunderland. 2017. Total mercury released to the environment by human activities. Environmental Science and Technology 51: 5969-5977.

Sullivan, S.M.P., L.E. Boaz, and K. Hossler. 2016. Fluvial geomorphology and aquatic-to-terrestrial $\mathrm{Hg}$ export are weakly coupled in small urban streams of Columbus, Ohio. Water Resources Research 52: 2822-2839. 
Summers, A.O., J. Wireman, M.J. Vimy, F.L. Lorscheider, B. Marshall, S.B. Levy, and L. Billard. 1993. Mercury released from dental silver fillings provokes an increase in mercuryresistant and antibiotic-resistant bacteria in oral and intestinal floras of primates. Antimicrobial Agents and Chemotherapy 37: 825-834.

Sunderland, E.M. 2007. Mercury exposure from domestic and imported estuarine and marine fish in the US seafood market. Environmental Health Perspectives 115: 235-242.

Sunderland, E.M., and N.E. Selin. 2013. Future trends in environmental mercury concentrations: Implications for preventions strategies. Environmental Health 12: 1-5.

Swain, E.B., P.M. Jakus, G. Rice, F. Lupi, P.A. Maxson, J.M. Pacyna, A. Penn, S.J. Spiegel, et al. 2007. Socioeconomic consequences of mercury use and pollution. Ambio 36: 45-61. https://doi.org/ 10.1579/0044-7447(2007)36\%5B45:SCOMUA\%5D2.0.CO;2.

Swanson, H.K., T.A. Johnston, D.W. Schindler, R.A. Bodaly, and D.M. Whittle. 2006. Mercury bioaccumulation in forage fish communities invaded by rainbow smelt (Osmerus mordax). Environmental Science and Technology 40: 1439-1446.

Sweet, L.I., and J.T. Zelikoff. 2001. Toxicology and immunotoxicology of mercury: A comparative review in fish and humans. Journal of Toxicology and Environmental Health-Part B-Critical Reviews 4: 161-205.

Swenson, J.J., C.E. Carter, J.C. Domec, and C.I. Delgado. 2011. Gold mining in the Peruvian Amazon: Global prices, deforestation, and mercury imports. PLOS ONE 6: e18875.

Tartu, S., A. Goutte, P. Bustamante, F. Angelier, B. Moe, C. ClémentChastel, C. Bech, G.W. Gabrielsen, et al. 2013. To breed or not to breed: Endocrine response to mercury contamination by an Arctic seabird. Biology Letters 9: 20130317.

Tartu, S., F. Angelier, J.C. Wingfield, P. Bustamante, P. Labadie, H. Budzinski, H. Weimerskirch, J.O. Bustnes, et al. 2015a. Corticosterone, prolactin and egg neglect behavior in relation to mercury and legacy POPs in a long-lived Antarctic bird. Science of the Total Environment 505: 180-188.

Tartu, S., A.Z. Lendvai, P. Blevin, D. Herzke, P. Bustamante, B. Moe, and O. Chastel. 2015b. Increased adrenal responsiveness and delayed hatching date in relation to polychlorinated biphenyl exposure in Arctic-breeding black-legged kittiwakes (Rissa tridactyla). General and Comparative Endocrinology 219: 165-172.

Tchounwou, P.B., W.K. Ayensu, N. Ninashvili, and D. Sutton. 2003. Environmental exposure to mercury and its toxicopathologic implications for public health. Environmental Toxicology 18: 149-175.

Thaiss, C.A., N. Zmora, M. Levy, and E. Elinav. 2016. The microbiome and innate immunity. Nature 535: 65-74.

Thompson, M., B.H. Coe, G.R. Andrews, D. Stauffer, D. Cristol, D. Crossley, and W.A. Hopkins. in press. Major global changes interact to cause male-biased sex ratios in a reptile with temperature-dependent sex determination. Biological Conservation.

Tilman, D., P.B. Reich, J. Knops, D. Wedin, T. Mielke, and C. Lehman. 2001. Diversity and productivity in a long-term grassland experiment. Science 294: 843-845.

Tirima, S., C. Bartrem, I. von Lindern, M. von Braun, D. Lind, S.M. Anka, and A. Abdullahi. 2016. Environmental remediation to address childhood lead poisoning epidemic due to artisanal gold mining in Zamfara, Nigeria. Environmental Health Perspectives 124: 1471-1478.

Turnbaugh, P.J., R.E. Ley, M. Hamady, C.M. Fraser-Liggett, R. Knight, and J.I. Gordon. 2007. The Human Microbiome Project. Nature 449: 804-810.

Tweedy, B.N., R.W. Drenner, M.M. Chumchal, and J.H. Kennedy. 2013. Effects of fish on emergent insect-mediated flux of methyl mercury across a gradient of contamination. Environmental Science and Technology 47: 1614-1619.

UNEP. 2013. Global Mercury Assessment 2013: Sources, emissions, releases, and environmental transport. Geneva: UNEP Chemicals Branch.

Vander Zanden, M.J., and J.B. Rasmussen. 1996. A trophic position model of pelagic food webs: Impact on contaminant bioaccumulation in lake trout. Ecological Monographs 66: 451-477.

Vander Zanden, M.J., J.M. Casselman, and J.B. Rasmussen. 1999. Stable isotope evidence for the food web consequences of species invasions in lakes. Nature 401: 464-467.

Vander Zanden, M.J., K.A. Wilson, J.M. Casselman, and N.D. Yan. 2003. Species Introductions and their impacts in North American shield lakes. In Boreal shield watersheds: Lake trout ecosystems in a changing environment, ed. J. Gunn, R.J. Steedman, and R. Ryder, 239-263. Boca Raton: CRC Press.

Varian-Ramos, C.W., J.P. Swaddle, and D.A. Cristol. 2013. Familial differences in the effects of mercury on reproduction in zebra finches. Environmental Pollution 182: 316-323.

Vitousek, P.M. 1994. Beyond global warming: Ecology and global change. Ecology 75: 186101876.

Vitousek, P.M., J.D. Aber, R.W. Howarth, G.E. Likens, P.A. Matson, D.W. Schindler, and D. Tilman. 1997. Human alteration of the global nitrogen cycle: Sources and consequences. Ecological Applications 7: 737-750.

Vorosmarty, C.J., and D. Sahagian. 2000. Anthropogenic disturbance of the terrestrial water cycle. BioScience 50: 753-765.

Vorosmarty, C.J., B.M. Fekete, M. Meybeck, and R.B. Lammers. 2000. Global system of rivers: Its role in organizing continental land mass and defining land-to-ocean linkages. Global Biogeochemical Cycles 14: 599-621.

Wada, H., D.A. Cristol, F.M.A. McNabb, and W.A. Hopkins. 2009. Suppressed adrenocortical responses and thyroid hormone levels in birds near a mercury-contaminated river. Environmental Science and Technology 43: 6031-6038.

Walters, D.M., D.F. Raikow, C.R. Hammerschmidt, M.G. Mehling, A. Kovach, and J.T. Oris. 2015. Methylmercury bioaccumulation in stream food webs declines with increasing primary production. Environmental Science and Technology 49: 7762-7769.

Wang, Y., J. Goodrich, B. Gillespiem, R. Werner, N. Basu, and A. Franzblau. 2011. A gene environment study of mercury in the Michigan Dental Association Cohort. Epidemiology 22: S134S134.

Wang, R., X. Feng, and W. Wang. 2013. In vivo mercury methylation and demethylation in freshwater tilapia quantified by mercury stable isotopes. Environmental Science and Technology 47: 7949-7957.

Wang, X., F. Wu, and W. Wang. 2017. In vivo mercury demethylation in a marine fish (Acanthopagrus schlegeli). Environmental Science and Technology 51: 6441-6451.

Ward, D.M., K.H. Nislow, C.Y. Chen, and C.L. Folt. 2010. Rapid, efficient growth reduces mercury concentrations in streamdwelling Atlantic Salmon. Transactions of the American Fisheries Society 139: 1-10.

Wenger, S.J., A.H. Roy, C.R. Jackson, E.S. Bernhardt, T.L. Carter, S. Filoso, and C.J. Walsh. 2009. Twenty-six key research questions in urban stream ecology: An assessment of the state of the science. Journal of the North American Benthological Society 28: $1080-1098$.

WHO. 2016. Technical paper \#1: Environmental and occupational health hazards associated with artisinal and small-scale gold mining. Geneva: WHO.

Wiener, J.G. 2013. Mercury exposed: Advances in environmental analysis and ecotoxicology of a highly toxic metal. Environmental Toxicology and Chemistry 32: 2175-2178. 
Wiener, J.G., M.B. Sandheinrich, S.P. Bhavsar, J.R. Bohr, D.C. Evers, B.A. Monson, and C.S. Schrank. 2012. Toxicological significance of mercury in yellow perch in the Laurentian Great Lakes region. Environmental Pollution 161: 350-357.

Wiles, G.J., J. Bart, R.E. Beck, and C.F. Aguon. 2003. Impacts of the brown tree snake: Patterns of decline and species persistence in Guam's avifauna. Conservation Biology 17: 1350-1360.

Willacker, J.J., C.A. Eagles-Smith, M.A. Lutz, M.T. Tate, J.M. Lepak, and J.T. Ackerman. 2016. Reservoirs and water management influence fish mercury concentrations in the western United States and Canada. Science of the Total Environment 568: 739-748.

Willson, J.D. 2017. Indirect effects of invasive species on ecosystems in south Florida. Journal of Applied Ecology 8: 975-989.

Wilson, M.L., E. Renne, C. Roncoli, P. Agyei-Baffour, and E.Y. Tenkorang. 2015. Integrated assessment of artisanal and smallscale gold mining in Ghana-Part 3: Social sciences and economics. International Journal of Environmental Research and Public Health 12: 8133-8156.

Wireman, J., C.A. Liebert, T. Smith, and A.O. Summers. 1997. Association of mercury resistance with antibiotic resistance in the gram-negative fecal bacteria of primates. Applied and Environmental Microbiology 63: 4494-4503.

Woodward, G., D.M. Perkins, and L.E. Brown. 2010. Climate change and freshwater ecosystems: impacts across multiple levels of organization. Philosophical Transactions of the Royal Society B-Biological Sciences 365: 2093-2106.

Wu, X.X., Y.M. Lu, S. Zhou, L.F. Chen, and B. Xu. 2016. Impact of climate change on human infectious diseases: Empirical evidence and human adaptation. Environment International 86: $14-23$.

Yamashita, Y., Y. Omura, and E. Okazaki. 2005. Total mercury and methylmercury levels in commercially important fishes in Japan. Fisheries Science 71: 1029-1035.

Yang, D.Y., Y.W. Chen, J.M. Gunn, and N. Belzile. 2008. Selenium and mercury in organisms: Interactions and mechanisms. Environmental Reviews 16: 71-92.

Zayas, L.H., and P.O. Ozuah. 1996. Mercury use in espiritismo: A survey of botanicas. American Journal of Public Health 86: $111-112$.

Zedler, J.B., and S. Kercher. 2005. Wetland resources: Status, trends, ecosystem services, and restorability. Annual Review of Environment and Resources 30: 39-74.

Zhang, H., X.B. Feng, T. Larssen, G.L. Qiu, and R.D. Vogt. 2010. In Inland China, rice, rather than fish, is the major pathway for methylmercury exposure. Environmental Health Perspectives 118: $1183-1188$.

Zhang, H., X.B. Feng, H.M. Chan, and T. Larssen. 2014. New insights into traditional health risk assessments of mercury exposure: Implications of Selenium. Environmental Science and Technology 48: 1206-1212.

Zhang, Q.F., Y.W. Li, Z.H. Liu, and Q.L. Chen. 2016. Exposure to mercuric chloride induces developmental damage, oxidative stress and immunotoxicity in zebrafish embryos-larvae. Aquatic Toxicology 181: 76-85.

\section{AUTHOR BIOGRAPHIES}

Collin A. Eagles-Smith $(\bowtie)$ is a Research Ecologist with the U.S. Geological Survey. His research interests focus on the interactions among ecological processes, contaminant bioaccumulation, and adverse effects on fish and wildlife.

Address: US Geological Survey, 3200 SW Jefferson Way, Corvallis, OR 97331, USA

e-mail: ceagles-smith@usgs.gov
Ellen K. Silbergeld is a Professor at the Johns Hopkin Bloomberg School of Public Health. Her research interests include heavy metal toxicity, antibiotic resistance, and food safety.

Address: Johns Hopkin Bloomberg School of Public Health, $615 \mathrm{~N}$. Wolfe Street, E6644, Baltimore, MD 21205, USA.

e-mail: esilber2@jhu.edu

Niladri Basu holds a Canada Research Chair in Environmental Health Sciences and is an Associate Professor at McGill University. His research interests span environmental toxicology to exposure science.

Address: McGill University, 204-CINE Building, Montreal, QC H9X 3V9, Canada.

e-mail: Niladri.basu@mcgill.ca

Paco Bustamante is Full Professor at the University of La Rochelle, laboratory of Littoral Environment and Societies. His main research topic includes the processes of bioaccumulation and detoxification of trace elements in marine organisms and their transfer in food webs. He pays a particular attention to the effects of mercury on marine top predators and their use to monitor and understand $\mathrm{Hg}$ biogeochemistry.

Address: University of La Rochelle, laboratory of Littoral Environment and Societies, Littoral Environnement et Sociétés (LIENSs), LIENSs UMR 7266 CNRS-Université de La Rochelle, 2 rue Olympe de Gouges, 17000 La Rochelle, France.

e-mail: pbustama@univ-lr.fr

Fernando Diaz-Barriga is a Director of the Center for Applied Research in Environment and Health at the Universidad Autonoma de San Luis Potosi. His research interests include assessment of exposure to chemicals and health risk at contaminated sites.

Address: Center for Applied Research in Environment and Health at, Universidad Autonoma de San Luis Potosi, Avenida Venustiano Carranza No. 2405, Col Lomas los Filtros Código Postal, 78214 San Luis Potosí, SLP, Mexico.

e-mail: fdia@uaslp.mx

William A. Hopkins is a Professor and Director of the Global Change Center at Virginia Tech. His research interests include physiological ecology and wildlife ecotoxicology, addressing pressing questions in both basic and applied sciences.

Address: Department of Fish and Wildlife Conservation, 310 West Campus Drive Virginia Tech, Cheatham Hall, Room 106 (MC 0321), Blacksburg, VA 24061, USA.

e-mail: hopkinsw@vt.edu

Karen A. Kidd is a Professor and Jarislowsky Chair in Environment and health at McMaster University. Her research interests include understanding the fate and effects of emerging and legacy contaminants in diverse aquatic food webs.

Address: Department of Biology \& School of Geography and Earth Sciences, McMaster University, 1280 Main Street W., Hamilton, ON L8S 4K1, Canada.

e-mail: karenkidd@mcmaster.ca

Jennifer F. Nyland is an Assistant Professor at the Salisbury University. Her research interests include immunotoxic effects of environmental contaminants.

Address: Department of Biological Sciences, 1101 Camden Ave, Salisbury, MD 21801, USA.

e-mail: jfnyland@ salisbury.edu 